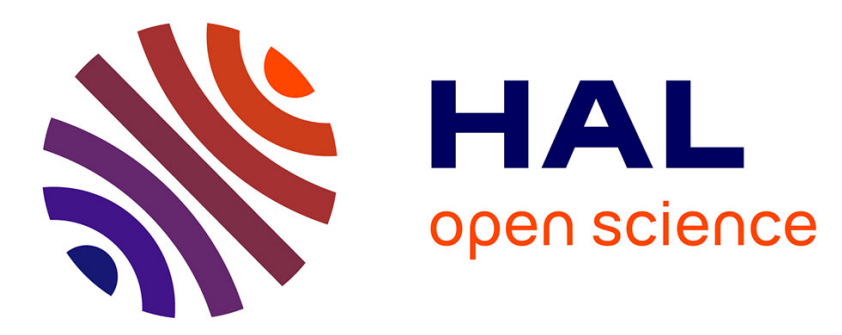

\title{
Lateral structure variations and transient swarm revealed by seismicity along the Main Himalayan Thrust north of Kathmandu
}

\author{
R. Hoste-Colomer, L. Bollinger, H Lyon-Caen, A. Burtin, L. Adhikari
}

\section{To cite this version:}

R. Hoste-Colomer, L. Bollinger, H Lyon-Caen, A. Burtin, L. Adhikari. Lateral structure variations and transient swarm revealed by seismicity along the Main Himalayan Thrust north of Kathmandu. Tectonophysics, 2017, 714-715, pp.107-116. 10.1016/j.tecto.2016.10.004 . hal-01992579

\author{
HAL Id: hal-01992579 \\ https://hal.science/hal-01992579
}

Submitted on 24 Oct 2019

HAL is a multi-disciplinary open access archive for the deposit and dissemination of scientific research documents, whether they are published or not. The documents may come from teaching and research institutions in France or abroad, or from public or private research centers.
L'archive ouverte pluridisciplinaire HAL, est destinée au dépôt et à la diffusion de documents scientifiques de niveau recherche, publiés ou non, émanant des établissements d'enseignement et de recherche français ou étrangers, des laboratoires publics ou privés. 
1 Title: Lateral structure variations and transient swarm revealed by seismicity along the

2 Main Himalayan Thrust North of Kathmandu

3 Authors: R. Hoste-Colomer ${ }^{(1)(2)}$, L. Bollinger ${ }^{(1)}$, H. Lyon-Caen ${ }^{(2)}$, A. Burtin ${ }^{(3)}$, L.B. Adhikari ${ }^{(4)}$

(1) CEA, DAM, DIF, F-91297 Arpajon, France.

(2) Laboratoire de Géologie, Ecole Normale Supérieure/CNRS UMR 8538, PSL Research University, Paris 75005, France.

(3) Institut de Physique du Globe de Paris, Sorbonne Paris Cité, Université Paris Diderot, UMR 7154 CNRS, Paris, France.

(4) Department of Mines and Geology, National Seismological Center, Kathmandu, Nepal.

Corresponding Author: Roser Hoste-Colomer

Phone: +33 169265463

e-mail: roser.hoste-colomer@cea.fr

\section{ABSTRACT}

The midcrustal seismicity along the Main Himalayan Thrust in Nepal presents lateral variations along the rupture of the 2015 Gorkha earthquake. In order to resolve these variations, we relocate the seismicity north of Kathmandu, during a period well covered by the Nepal National Seismological Network, using a double-difference algorithm. The 550 relocated events highlight a complex pattern of clustered seismicity within the unstablestable transition zone. Part of the seismicity is densely clustered on a southward dipping plane which ruptured on January $31^{\text {st }} 1997(\mathrm{ML}=5.8)$, activating a backthrust with a geometry consistent with the centroid moment tensor of this event calculated in this study. 

35 44

At its eastern end, the midcrustal cluster is offset by $20 \mathrm{~km}$ to the south suggesting the presence of a tear fault. The analysis of the time sequence allows constraining a scenario involving stress transfer between these local midcrustal structures, beginning more than one month before the 1997 main shock. The temporal evolution of the seismicity is strikingly similar for two other transient seismic swarm episodes which developed hundreds of kilometers apart along the Main Himalayan Thrust at the same time. The local stress field appears responsible for the higher sensitivity of these regions to subtle strain transients developing along the Main Himalayan Thrust.

Key words: seismicity, Main Himalayan Thrust, fault segmentation, relative relocation.

(1) 36

.

38

39

40

\section{1} 2 43 


\section{Introduction}

Along-strike variations of seismic activity on a fault can result from lateral variations in the geometry of the locked fault zone, spatial heterogeneity in frictional parameters or from unsteady loading during the interseismic period. Variations in seismicity rates along the downdip end of a locked megathrust may reveal that the structure is segmented, and these segment boundaries may correspond to the barriers that delimit major seismic ruptures (e.g. Schwartz et al., 1989; Collot et al., 2004; Métois et al., 2012; Holtkamp et al., 2011; Holtkamp and Brudzinski, 2011). The Main Himalayan Thrust (MHT) fault in Nepal qualifies as one interesting fault to document in terms of seismicity variations given its seismogenic potential and the possible control of the coseismic ruptures by persistent structural features (e.g. Grandin et al., 2015). Indeed, despite the apparent homogeneity of the stress build up revealed by geodesy (Ader et al., 2012; Stevens and Avouac, 2015) significant variations of the seismic rate have been reported along strike (Pandey et al., 1999). Some of the variations in seismic rate are persistent in time and might reveal lateral heterogeneity in terms of seismic coupling and/or tectonic structures along strike of the MHT. Others are temporary, related to transient episodes including swarm activity or mainshock-aftershock sequences.

On April 252015 at 11 h56 Nepal Standard Time (06h11 UTC), the Mw 7.8 Gorkha earthquake ruptured a $120 \mathrm{~km}$-long and $35-50 \mathrm{~km}$ wide fault segment of the MHT (e.g., Avouac et al., 2015; Grandin et al., 2015; Kobayashi et al., 2015; Elliott et al., 2016)(Figure 1), abutting the great M8.2 1934 earthquake rupture. The propagation of the rupture and the slip along the fault plane were heterogeneous, leading some authors to suggest possible 
along strike variations of the structure at depth (Grandin et al., 2015, Fan and Shearer, 2015).

The aftershocks near the trace of the rupture in the vicinity of Kathmandu are heterogeneously distributed (Adhikari et al., 2015; Bai et al., 2015). Some aftershocks are clustered under Kathmandu valley, a place where no seismicity has been observed during the interseismic period (Figure 1). In the meantime, north of the Nepalese capital, the aftershocks epicenters coincide with the location of the midcrustal interseismic cluster (10$20 \mathrm{~km}$ depth) (Figure1). The heterogeneous distribution of the Gorkha earthquake aftershocks and the seismicity during interseismic period north of Kathmandu could be due to structural complexities or a transient event. The goal of our study is to use small earthquakes prior to the 2015 Gorkha event to resolve structural and frictional characteristics that might control the rupture parameters of the main shock.

In order to test such a hypothesis, we analyze the spatio-temporal variations of the seismicity during the interseismic period north of Kathmandu, a region well covered by the Nepalese national seismological network. We first relocate the seismic events using a double-difference algorithm (Waldhauser and Ellsworth, 2000) and perform a Centroid Moment Tensor inversion of the largest instrumentally recorded event in the region, $M L=5.8$ on January $31^{\text {st }} 1997$. We then interpret the spatial pattern of seismicity in terms of geological structures at depth, and finally focus on the temporal variation of the seismicity rate along this structure.

\section{Data description}

\subsection{Regional Network}


The seismicity of central and eastern Nepal has been continuously monitored since the 1990s by the National Seismological Centre of Nepal (NSC) with a national network composed of 21 short period vertical component seismic stations. Among them 12 high gain stations have been operational since 1994 in central and eastern Nepal providing a completeness of the seismic catalogue for that region around local magnitude $\mathrm{ML}=2.0$ (Pandey et al., 1999). Their records are processed using Jade-Onyx acquisition-treatment software in which a 1D velocity model is used to locate earthquakes using the phases picked manually at NSC (Pandey, 1985; Pandey et al., 1995, Adhikari et al., 2015). A complementary network of 3 stations was deployed temporarily, from July 1995 to December 1996 . The addition of these stations facilitated improved locations for the small earthquakes generated at midcrustal depths below the front of the high topography (Cattin and Avouac, 2000) in the vicinity of the Main Himalayan shear zone (Nabelek et al., 2009).

\subsection{Earthquake catalogue}

North of Kathmandu, the interseismic activity appears concentrated at midcrustal depths within a permanent seismic cluster (Pandey et al., 1995; Cattin and Avouac, 2000) (Figure 1) modulated by a few transient seismicity bursts (Figure 2). The most important seismicity burst was recorded in 1997. Indeed, $30 \%$ of the $M L>=4.0$ events of the catalogue in this region occurred in that year (Figure 2). The sequence culminated after the occurrence of the "Sarshin earthquake" an ML=5.8 event which happened on January $31^{\text {st }} 1997$ (Table 1), an event preceded 3 hours before by a foreshock of ML 5.1. This event resulted in a maximum shaking intensity of MMI VII and was felt in Kathmandu $40 \mathrm{~km}$ SE from its epicenter. It caused significant impact (MMI VI) over a region $1800 \mathrm{~km}^{2}$ in size (Sapkota, 2011). Given its magnitude, this event was also recorded at teleseismic distances by international 
112 institutions, which assigned a body-wave magnitude ( $\mathrm{mb}$ ) around 5.2 and depths between

11317 and $23 \mathrm{Km}$ (Table 1).

114 The Sarshin earthquake was followed by more than 160 aftershocks in a region spanning 50

$115 \times 30 \mathrm{~km}^{2}$, a surface significantly larger than the expected rupture extension. The orientation

116 of the seismic cluster based on NSC locations is unclear and we expect that relocated

117 aftershocks will help to constrain the geometry of the structure activated by the Sarshin 118 earthquake.

119 3. Method

\section{$120 \quad$ 3.1. Centroid Moment Tensor at regional scale}

121 Seismic data of the 1997 Sarshin earthquake recorded by stations at distances up to $1700 \mathrm{~km}$

122 and of good quality are used to calculate a Centroid Moment Tensor. This includes data from

123 stations LSA (Tibetan plateau), HYB (central India), WUS (northern China) and CHTO

124 (Thailand) (Figure 3).

125 The centroid moment tensor solution is retrieved from the inversion of regional long-period

126 seismic waves (40-100s). The procedure is taken from Nábelek (1984) and is adapted to a

127 low-frequency inversion (Nábelek and Xia, 1995). For the centroid moment tensor inversion,

128 a 1-D velocity structure should be chosen to compute synthetic Green's functions and model

129 the observed waveforms at seismic stations. Processing a large number of events (29

130 earthquakes in (Burtin, 2005) and 107 earthquakes in (Baur, 2007) in the Himalaya and

131 Tibetan Plateau regions) we failed to correctly invert the seismic waveforms at stations with

132 a single velocity model. Seismic signals from sources occurring along the Himalayan arc were

133 recorded at stations located around the Tibetan plateau and the India plate. Therefore,

134 velocity structures through which seismic waves travel can drastically change. For instance 
when a velocity model with a Moho depth fixed at $35 \mathrm{~km}$ (ex. India path) is used, the modeled waveforms for northern Tibetan stations will systematically arrive sooner than the observed ones. To overcome this issue, each ray path is associated with a specific 1-D structure. For the Indian station HYB, the model is from Saul et al., (2000) with a Moho depth at $35 \mathrm{~km}$. For the Tibetan station LSA and northern China station WUS, the model is modified from Haines et al., (2003) with a Moho depth at $65 \mathrm{~km}$. In this latter model, we had to remove the $5 \mathrm{~km}$ thick sedimentary layer because otherwise the synthetic inverted seismic waves were delayed too much. Finally, the model for the Thai station CHTO was set to an intermediate model between the Indian and Tibetan models with a Moho depth at 45 $\mathrm{km}$. These velocity models were tested using a trial and error procedure on the 29 focal mechanisms studied (Burtin, 2005); we retained those models that resulted in synthetics that best matched the observed seismic data (Figure 3) - See Burtin, 2005 for further information. Furthermore, for each earthquake analyzed in Burtin (2005), including the Sarshin earthquake, the centroid moment tensor source depth was constrained through a grid search algorithm that minimized the waveform misfit, using at first a coarse step size (10 $\mathrm{km})$ followed by a finer step size $(1 \mathrm{~km})$.

\subsection{Relative relocation at local scale}

We calculate relocations using the double-difference algorithm HypoDD (Waldhauser and Ellsworth, 2000) for the seismicity clustered north of Kathmandu, in the trace of the Gorkha earthquake. We use data from the NSC bulletin for the period 1996-1999 and the whole bulletin from the temporary experiment of 1995-1996. Relative locations are resolved by solving an inverse problem using a damped least-square technique, minimizing the residuals between observed and calculated phase delay times between a pair of adjacent earthquakes 
recorded at common stations. This procedure reduces the biases induced by velocity model errors along the paths from hypocenters to seismic stations. The velocity model considered hereafter is the 1-D model of Pandey (1985) with a Vp/Vs of 1.73 . We initially attribute to each seismic event the origin time and hypocenter of the NSC seismic bulletin. We also allocate location errors corresponding to the average of the longitudinal and latitudinal uncertainties as well as depth uncertainties documented in the bulletin. Undetermined depths in the database are fixed to 0 . The second set of inputs include the arrival times of $P$ and $\mathrm{S}$ phase arriving at a station for a given event. The weight for the $\mathrm{P}$ phases is fixed to 1 and for the S phases to 0.3 .

Given the very high density of events located immediately in the vicinity of the Sarshin earthquake, compared to the more diffuse spatial and temporal pattern of the seismicity elsewhere, we divide the catalogue of events in two, a western and an eastern region (respectively zones 1 and 2 hereafter) separated at 85.4E (Figure S1 and S3). This division will enable us to better optimize the relocation process.

We select pairs of phases at every station considering (1) a maximal separation between hypocenters of $20 \mathrm{~km}$ and (2) a minimum number of links between two neighbor events of 8 for Zone 1 and of 4 for Zone 2.

The relocation is performed in both cases with $\mathrm{P}$ and $\mathrm{S}$ phases when available and with three sets of iterations taking into account the seismic bulletin parameters. We set the damping at 20 in a LSQR inversion. The first set iterates four times using only $P$ waves. The second set iterates also four times with $\mathrm{P}$ and $\mathrm{S}$ waves. The third set iterates 8 times taking into account $\mathrm{P}$ and $\mathrm{S}$ waves, limiting the residuals to 5 seconds and the maximum distance between linked pairs to $10 \mathrm{~km}$. The relocation of Zone 1 considers 8 as the minimum number of links per pair 
to form a continuous cluster. There is no clustering a priori parameter for the relocation of Zone 2.

We tested the most influential parameters for both the pair-phase selection and the relocation process. In the pair-phase selection, we tested values at 4,8 , and 12 for the minimum number of links between two neighbor events. We also tested maximum separation between hypocenters at 20 and $50 \mathrm{~km}$. The number of pair-phases created increase considering either a larger number of minimum links per pair or a larger maximum separation distance between hypocenters, however there are more events weakly linked. The minimum number of links between two neighbor events tested changes in Zone 1 and 2 because of the density of events. We also tested various numbers of iterations ( 4 and 8 for each set) in the relocation process. The RMS misfit decreases for the first two sets until it stabilizes after 4 iterations. The solution becomes unstable with 8 iterations, resulting in a centroid shift and in an unstable RMS misfit. In the third step, 8 iterations are needed to stabilize the RMS misfit. Geometrically, the relative relocations were similar for any iteration scheme.

The tests results support the parameters we chose for Zone 1 and 2.

\section{4- Results}

In Zone 1 (Figure 4), the seismic bulletin includes 230 events with 2408 phases from which 20140 P-phases pairs and 12469 S-phase pairs are found. 80\% of P-phase pairs and $84 \%$ of Sphase pairs are selected. The event pairs have an average of 10 links with an average offset of $6.04 \mathrm{~km}$. After event pair selection, 167 events are successfully relocated, with less than $1500 \mathrm{~m}$ of 2-sigma-relative location errors in $x, y, z$ and a RMS misfit reduction of $60 \%$ (Figure S2, S3, S5, and S6). 
The seismic bulletin covering Zone 2 (Figure 4) includes 548 events with 4886 phases from which 45938 P-phase and 39002 S-phase pairs are determined. Respectively, 49\% and 45\% of P- and S-phase pairs are selected. The event pairs have an average of 6 links with an average offset of $6.9 \mathrm{~km} .477$ events are selected, from which 384 events are successfully relocated with less than 100 m of 2 -sigma-relative location errors in $x, y, z$. The RMS misfit reduction, following the integration of the phases picked at the temporary 3 component stations, is close to $90 \%$ (Figure S2, S3, S4, S5, S6, and S7).

The relocation of Zone 1 and Zone 2 seismicity indicates the presence of two separate clusters during the 1997 seismic episode (Figure 4). The westernmost seismic cluster is located between $85.3^{\circ}$ and $85.4^{\circ}$, covering an area of $7 \times 11 \mathrm{~km}^{2}$ (Figure 4, map), just above the January $31^{\text {st }}$ Sarshin earthquake hypocenter (Figure 4, cross-section). The visual inspection of $3 \mathrm{D}$ plots shows that the seismicity lies on a plane that strikes $\mathrm{N} 050 \pm 20 \mathrm{E}$ dipping steeply southeast $\left(70-80^{\circ}\right)$. The other seismic cluster is smaller $\left(6 \times 8 \mathrm{Km}^{2}\right)$ and is located between $85.4^{\circ}$ and $85.5^{\circ}$. It describes an almost vertical plane striking $\mathrm{N} 155 \pm 20 \mathrm{E}$ (Figure 4). No large event is associated with this cluster. The remaining relocated seismic events do not show a particular geometry. Most of them are located in a $10 \mathrm{~km}$-wide band east of $85.5^{\circ}$.

The centroid moment tensor solution for the January $31^{\text {st }}$ Sarshin earthquake indicates a best centroid depth at $17 \mathrm{~km}$ and a reverse motion with a slight strike-slip component. One nodal plane (NP1) strikes N075 and dips $85^{\circ} \mathrm{SE}$, and the second (NP2) strikes N152 and dips $24^{\circ} \mathrm{NE}$. Although it is difficult to quantify uncertainties on the centroid moment tensor solution, the azimuthal coverage being decent and the changes in centroid moment tensor being small in the vicinity of the best depth, we consider the uncertainties to be moderate 

in the inversions. The NP1 plane is the closest to the plane defined by the relocated aftershocks of the Sarshin earthquake. The moment magnitude obtained is $\mathrm{Mw}=4.8$.

The depths of the relocated events range from 15 to $26 \mathrm{~km}$ in the western cluster, with the main shock at $24 \mathrm{~km}$ depth which is slightly deeper than previous determinations (Table 1 ).

232 NSC gives a hypocenter at $20.3 \mathrm{~km}$ while the centroid moment tensor centroid depth is at 17 $\mathrm{km}$. Although the relocation allows us to place constraints on the relative positions of hypocenters leading to a fairly well defined geometry for the cluster, the centroid depth of the cluster $(\sim 22 \mathrm{~km})$ is less well constrained as the closest station that recorded these events is located at $\sim 25 \mathrm{~km}$, and thus the centroid could move by a few kilometers. Both hypocenter depths and centroid moment tensor centroid depths being within $+/-5 \mathrm{~km}$, we think the differences may not be significant. In addition, as most crustal earthquakes nucleate at depth and propagate towards the surface (e.g., Das and Scholz, 1983; Huc et al., 1998), we expect the hypocenter depth of the mainshock to be larger than its centroid

241 moment tensor depth. This will be particularly true if the co-seismic slip is small and the 242 ruptured area large for a Mw4.8 event. Indeed, the source of a Mw4.8 can be either $2 \times 2 \mathrm{~km}^{2}$ 243 with $10 \mathrm{~cm}$ of slip or $5 \times 5 \mathrm{~km}^{2}$ with $2 \mathrm{~cm}$ of slip.

\section{5-Interpretation}

\section{Spatial distribution of the Sarshin Swarm}

246 Most of the 1996-2000 Sarshin Swarm seismicity is located at midcrustal depths, with centroid depths at 22 and $15 \mathrm{~km}$ respectively for the two clusters (Figure 4). These depths roughly correspond to the depth of the Main Himalayan shear zone, as interpreted on 
images obtained along profiles based on receiver function analysis (Schulte-Pelkum et al., 2005; Nabelek et al., 2009; Duputel et al., 2016).

251

The westernmost cluster develops after the main shock of the Sarshin earthquake over a $7 \mathrm{x}$ $11 \mathrm{~km}^{2}$ region. Given the geometry of the cluster and the fault plane solution parameters of its main shock, the January $31^{\text {st }} 1997$ Sarshin earthquake, we associate this seismic swarm to the activation of a NE-SW backthrust, steeply dipping to the southeast. Assuming that the aftershock distribution corresponds to the maximum extent of the fault segment ruptured by the main shock, a $\mathrm{Mw} 4.8\left(\mathrm{MO}=2.3^{*} 10^{16} \mathrm{Nm}\right.$ deduced from the centroid moment tensor determination), and assuming a shear modulus of 32GPa we obtain an average minimum slip of $1 \mathrm{~cm}$. Considering that aftershocks may more likely extend beyond the edges of the ruptured plane, its surface is likely overestimated. A surface overestimation by $100 \%$ will lead to doubling the average slip, at $2 \mathrm{~cm}$. This amount of slip at depth induces infra-mm displacements at the surface GPS sites around, values below the resolution capacity of the campaign GPS available at that time (Jouanne et al., 2004).

A rupture on a steep south-eastward dipping - northwestward verging thrust at mid-crustal depths below the front of the high topography may correspond either to the activation of (a) a fault segment at the forelimb of the lesser Himalayan duplex (e.g. Pearson and DeCelles, 2005; Khanal and Robinson, 2013), or (b) a local shear zone within the hinge above the flatdecollement/ramp, as predicted by mechanical models (Souloumiac et al., 2009) (Figure 7D). We prefer the latter interpretation, as the depth seems more consistent with the downdip end of a midcrustal ramp than the passive roof-thrust of the duplex.

The relocated seismicity appears offset by $20 \mathrm{~km}$ from west to east, describing an eastward right-stepping strand. Note that this step is not an artifact due to the location of the 
boundary between the two zones considered in the relocation process: alternative

273

relocations considering only one zone, keeping the same relocation parameters, produced similar spatial patterns, with the seismic cluster stepping to the south in this area. This offset could be explained by the presence of a tear fault between two ramps or structural discontinuities within the Main Himalayan shear zone such as a stepover of the fault. We prefer the former hypothesis given the absence of overlapping seismicity along strike. In addition, the vertical NW-SE plane described by the second cluster $\left(85.4^{\circ}\right.$ and $\left.85.5^{\circ}\right)$ identified in the relocation results is consistent with tear faulting although we could not compute any fault plane solution to prove this. Such tear faults are required because of the topology of the MHT flat/ramp system and its lateral variations (Figure 7). The right lateral tear fault suspected to develop at depth within the trace of the second cluster is aligned with an active dextral fault system reaching the surface along the $20 \mathrm{~km}$-long NNW-SSE Jhiku Khola fault (Kumahara et al., 2016).

We propose that the backthrust and tear fault activated during the 1997 seismic episode, and in a more general way every significant variation of the structure at depth along the MHT, might influence its behavior. It could affect the propagation of the co-seismic rupture (e.g. Béjar-Pizarro et al., 2010), influencing the co- and post-seismic slip distribution as well as the location of the aftershocks. Note that the structure we studied is located in between two patches of maximum slip of the Gorkha earthquake proposed by some authors (e.g. Avouac et al., 2015; Grandin et al., 2015) (Figure 1).

\section{$\underline{\text { Temporal distribution of the seismicity at local and regional scales }}$}


The time structure of a seismic episode gives a dynamic sense and evolution of the

294

295

296

297

298

299

300

301

302

303

304

305

306

307

308

309

310

311

312

phenomenon that the spatial distribution does not. Both are essential to interpret our results.

The time structure of the seismicity in this area (Figure 4) exhibits complex variations in the period covered by our study. The seismicity rate decreases first in mid-1996 (Figure 2 and 5). This relative quiescence is difficult to ascertain, being concurrent with the monsoon arrival, a period during which the seismic noise level and therefore the completeness magnitude of the catalogue is higher than on average, a period during and slightly after which the seasonal load of the india plate has a genuine influence on the seismicity (Bollinger et al., 2007; Bettinelli et al., 2008; Burtin et al., 2008). The seismic rate remains low until December, far after the monsoon period, and is followed by a sharp increase. The seismic events are then clustered between $85.4^{\circ}$ and $85.5^{\circ}$ (Central zone in Figure 4), mostly along a $6 \mathrm{~km}$-long vertical plane oriented N155. This activity, decreasing at the beginning of 1997, is followed by the development of another cluster $15 \mathrm{~km}$ to the northwest in January (Figure 4,5 ). The swarm in the area begins before the Sarshin main shock which occurred at 20:02 (local time) on January 31st and was preceded by a ML5 and smaller events a few hours earlier. The seismic cluster that developed within the next three months within $10 \mathrm{~km}$ from the hypocenter is typical of an aftershock sequence. In the meantime, the seismicity rate east of $85.5^{\circ} \mathrm{E}$ increased significantly (Figure 5).

Surprisingly, this unusual transient seismic activity is not exceptional in the Himalaya region. Indeed, in eastern Nepal, a seismic swarm developed between 86.8 and $87^{\circ} \mathrm{E}$, generating 80 events south of Mount Everest, between November 1996 and May 1997. No main shock was detected prior to the onset of the seismic swarm but a larger shock, with a ML 5.8, occurred on the 30/12/1996 (Table 1) and was followed by aftershocks (Figure 6). In western Nepal, 
between $80.5^{\circ}$ and $81^{\circ} \mathrm{E}$, a similar swarm developed with a main shock on $05 / 01 / 1997$ of $M L=6.3$ (Table 1). The location of the seismicity in these two areas is not sufficiently resolved to perform an analysis similar to what has been done here. The time structure of these two swarms is very similar to that of Sarshin as illustrated on Figure 6.

Altogether, the 3 clusters contribute to $40 \%$ of the yearly midcrustal events detected along the front of the range in Nepal. Their cumulative along strike development accounts for $\sim 10$ $\%$ of the length of the midcrustal cluster making this event the most important seismicity burst of the interseismic period recorded by the Nepal National Seismological Network. No significant seismic rate variations were detected in between the three clusters (Figure 6).

\section{6- Discussion}

Complex spatial and temporal variations of seismicity have been revealed at local and regional scales. Locally, north of Kathmandu, the spatial distribution of the seismicity coincides with a back-thrust and a thrust segment separated by a proposed $20 \mathrm{~km}$-long tear fault. Their consecutive activation follows the development of a seismic swarm on the tear fault. The geometry of the fault system is consistent with a right lateral slip on the tear fault. This scenario is compatible with the topology of the thrust system as well as with the kinematics of the dextral NNW-SSE Jhiku Khola fault described in continuity to the south (Kumahara et al., 2016). The en-echelon segments of the MHT there are close to the unstable-stable transition zone USTZ (e.g. Jackson and Bilham, 1994; Bettinelli et al., 2006). This behavior was confirmed recently by the determination of the seismic coupling that falls there between 0.4 and 0.6 (Ader et al., 2012; Grandin et al., 2012; Stevens and Avouac, 2015).

The seismic activity in 1997 in this region could result from (1) a local unsteady loading or (2) a local strain transfer in the vicinity of the USTZ. However, rather than just a local strain 
transient, the development in 1996-97 of 2 other clusters hundreds of kilometers apart, depicting similar temporal variations, may imply (3) a large scale unsteady loading. The unsteady loading could be due, among others, to a lithospheric response to the water mass redistribution after the monsoon or to a slow slip event. However, in 1996, the precipitation records were fairly typical (e.g., Shrestha et al., 2000; Yatagai et al., 2012). This leads us to propose that the 1997 seismic episode may be related to a slow slip event. A transient slip event with a slip amplitude of tens of centimeters is precluded due to the absence of measurable changes in the seismicity rate between the clusters (Figure 6A). Indeed, a seismicity change would likely occur after a centimetric to decimetric scale slow slip event, which would in turn release years of stress build up and therefore most probably induce years of midcrustal seismicity along strike. The lower end of the slip amplitude expected, i.e. $1 \mathrm{~cm}$, would correspond roughly to the seismic slip accommodated during the Sarshin earthquake (see previous section for estimation). In Sarshin area, such an amount of slip at midcrustal depths generates only infra-milimetrical displacements at RAMO and SYAO, regional GPS stations respectively 17 and $20 \mathrm{~km}$ from the updip-end of the ruptured fault plane. These stations were surveyed briefly in 1995 and 1998 (1 to 4 days/sessions). They were translated in 3 years by $19 \pm 6 \mathrm{~mm}$ and $21 \pm 7 \mathrm{~mm}$ respectively in an India fixed reference frame (Jouanne et al., 2004). The large uncertainties of the measurements preclude resolving the infra-milimetrical displacements induced by the Sarshin earthquake as well as those induced by any strain transient with similar amplitudes. We further note that the displacements uncertainties for both stations amounts to one third of the measurements, a value comparable to one year of strain above the Main Himalayan Thrust. The thrust accommodates, at depth, on average, a shortening of $18 \mathrm{~mm} / \mathrm{yr}$ (Ader et al., 2012). Detecting a transient slip event at depth on the creeping part of the MHT of less than $18 \mathrm{~mm}$ 
therefore seems impossible. This result is corroborated by the absence of any major change in the shortening rates estimated elsewhere in Nepal by campaign GPS data, and by the continuous DORIS time series available at Everest.

Several of the large transient events elsewhere in the world were accompanied by tremors and low frequency earthquakes (Schwartz and Rokosky, 2007). Such kinds of seismic events have not been observed in 1997 in Nepal, a period during which the continuous seismic signals recorded by National Seismological Network was not stored. Further analysis of these signals to detect tremors or low frequency earthquakes is therefore limited to the cut signals of seismic events which, according to a preliminary analysis, present a typical spectra.

Despite the lack of direct evidence that tremors and low frequency earthquakes occurred, we think the seismic catalogue contains other indirect evidences of this process.

A subtle transient slip event may generate heterogeneous seismicity along strike due to the geometry and state of stress changes along strike of the MHT. Indeed, the midcrustal seismicity under the front of the Himalayas appears sensitive to the local state of stress which depends mainly on the regional tectonic stress and the topography, through their influence on the preferred orientation of the failure planes (Bollinger et al., 2004a). In between the Main Frontal Thrust and the front of the High range, S3 and S1, the minimal and maximal principal stresses, are respectively vertical and north-south. S1 increases during interseismic deformation due to slip at depth on the $\mathrm{MHT}$, promoting failure on EW striking thrust planes (Figure 7A(area 2)). Further north, in the Southern Tibetan grabens (Figure 6B), S1 is vertical while S3 is horizontal, striking approximately east-west. S3 might decrease during interseismic deformation (Figure 7A(area 3)), since east-west extension increases in the Southern Tibetan Graben due to the divergence of thrusting along the Himalayan Arc (Bollinger et al., 2004a). This promotes failure on north-south oriented normal faults (ie: the 
southern Tibetan grabens). In between these two domains (i.e. south of the range, Tibetan Plateau: between area 2 and 3 on Figure 7A) the regional state of stress might promote the existence of NW-SE and NE-SW strike slip faults. This is valid for a range of depths in the cluster which depends on both S1 and S3 and the local non compensated topography. In this area, the intermediate stress component is vertical, while the maximum and minimum principal stresses correspond respectively to the north-south and east-west stress values (Figure $7 \mathrm{~A}($ area 1$))$. The strike slip faults in this region are very sensitive to the simultaneous N-S and E-W stress variations (Figure 7A). The lack of strike slip Centroid Moment Tensor solutions for intermediate events $(M>5.5)$ during the last decades along the Himalaya demonstrate that strike slip faulting is infrequent along strike, probably due to the restriction to a small depth range of the corresponding state of stress. Besides the presence of large scale active strike-slip faults affecting the lesser Himalayas (Nakata, 1989), interpreted as resulting from large scale strain partitioning (Nakata, 1989; Murphy et al., 2014) or from the presence and migration of lateral ramps (Bollinger et al., 2004b), few active strike-slip fault segments were described at the foot of the High range (Nakata, 1989). However, tear-faults are suspected at midcrustal depths because of the lateral variations of the midcrustal ramps along the strike of the Main Himalayan thrust (e.g. Robinson et al., 2001; Bollinger et al., 2004b; Grandin et al., 2012). Despite the publication of balanced cross sections immediately west of Sarshin area (e.g. Pearson and Decelles, 2005; Khanal and Robinson, 2013), the present-day positions of the midcrustal ramps in the vicinity of the seismic cluster studied here are still unresolved. Assuming the cluster represents the edge of the MHT locked segment (e.g. Cattin and Avouac, 2000; Bollinger et al., 2004; Ader et al., 2012, Grandin et al., 2015), a dextral NW-SE transform structure is required for the sake of geometrical continuity (Figure 4 and 5, Central zone in blue). Assuming that this swarm is 
located on such a right lateral strike slip segment, its activity in December 1996 creates static

stress changes at its extremities. It leads to the generation of 2 positive Coulomb stress variations (DeltaCFF) lobes on its NW and SE sides (while NE and SW would see a negative DeltaCFF(Figure S8 to S11 and Table S2). This static stress change scenario accounts for the generation of seismicity along the backthrust to the NW and the thrust to the SE as well as with the lack of microseismic activity along its NE and SW extremities (Figure 7B and 7C). Furthermore it is consistent with Sarshin focal mechanism depicting a NE-SW oriented fault plane solution (Figure 4).

Whether similar kinematics and mechanisms are involved in the generation of the Far western and eastern Nepal seismic swarms is unknown. Unfortunately, the seismicity in these regions cannot be analyzed with a similar relocation approach due to the less optimal geometry of the seismic network and completeness of the database. But the 3 swarms are located in similar settings, within the midcrustal cluster at similar distances from the USTZ and within the trace of southern Tibetan Grabens (Figure 6B). Another similarity is their time sequence that begins with a weak but detectable decrease of seismicity prior to the swarms' development (Figure 6A). These rate decreases begin about 6 months prior to each swarm, during the onset of the monsoon. That the higher level of seismic noise during the monsoon is responsible for the seismic rate decrease is possible (Bollinger et al., 2007), but the rate remains low after the end of the monsoon and the decrease of the seismic noise generated by landsliding and rivers (Burtin et al., 2008). An alternative interpretation could be that the seismicity was partially inhibited and then promoted due to the response of the crust to a loading/unloading of continental water (Bettinelli et al., 2008; Chanard et al., 2014) in 1996. Whatever the scenario, the simultaneous development of these swarms may have resulted from a transient slip event similar to those detected along other subduction zones (e.g. 
Cascadia, Mexico, Japan,...) with an affected area between 30 to $600 \mathrm{~km}$ along strike, and

transient slip lasting 6 days to about a year with amplitudes between $5 \mathrm{~mm}$ and $5.6 \mathrm{~cm}$ (e.g.

439 Dragert et al., 2001; Schmidt and Gao, 2010; Schwartz and Rokosky, 2007; Szeliga et al., 440 2008).

441 Such a slow slip event occurring on the Main Himalayan Thrust could play a role in the 442 seismic cycle of the locked segment of the fault. Indeed, such transient events bring the 443 locked fault zone closer to failure by several months (Dragert et al., 2001), besides the 444 interseismic loading on the fault.

\section{7- Conclusion}

The first conclusion to be drawn from this work is that the downdip end of the locked section of the Main Himalayan Thrust exhibits lateral seismicity variations that may reveal the presence of structural complexities at midcrustal depths. The right-stepping geometry of the seismicity, north of Kathmandu, is interpreted as resulting from the activation of a tear

450 fault between a backthrust and a thrust segment. This structural complexity might have influenced the slip distribution during the Gorkha earthquake rupture as revealed by a local

452 minima in the region of high slip of some published slip models. A second major conclusion 453 is that the time sequence of the seismic swarm which developed there in 1996-97 is 454 consistent with a propagation of a local strain transient, from the tear fault to the backthrust 455 and thrust. Finally, the temporal coincidence between this swarm and two others at far distances leads us to suspect the development of a larger-scale transient slip event on the 457 Main Himalayan Thrust. The local stress field appears responsible for the higher sensitivity of 458 these areas to strain transients and needs therefore to be monitored to ascertain the 459 presence of infrequent subtle slow slip events along the Himalaya. 
This project is funded by the French Agence Nationale de la Recherche (ANR-13-BS06-000601) and the Comissariat à l'Energie Atomique et aux Energies Alternatives. We thank the National Seismological Centre, Sudhir Rajaure and Soma Nath Sapkota for early exchanges on the seismic catalogue and macroseismic field of the Sarshin earthquake. The authors also thank the two anonymous reviewers and Gavin P. Hayes for their helpful comments that improved the paper.

\section{References}

Ader, T., Avouac, J.P., Liu-Zeng, J., Lyon-Caen, H., Bollinger, L., Galetzka, J., Genrich, J., Thomas, M., Chanard, K., Sapkota, S.N., Rajaure, S., Shrestha, P., Ding L. and Flouzat, M., 2012. Convergence rate across the Nepal Himalaya and interseismic coupling on the Main Himalayan Thrust: Implications for seismic hazard, Journal of Geophysical Research, 117, B04403, doi: 10.1029/2011JB009071.

Adhikari, L.B., Gautam, U.P., Koirala, B.P., Bhattarai, M., Kandel, T., Gupta, R.M., Timsina, C., Maharjan, N., Maharjan, K., Dahal, T., Hoste-Colomer, R., Cano, Y., Dandine, M., Guilhem, A., Merrer, S., Roudil, P. and Bollinger, L., 2015. The aftershock sequence of the 2015 April 25 Gorkha-Nepal earthquake, Geophysical Journal International, 203, 2119-2124, doi: 10.1093/gji/ggv412.

Armijo, R., Tapponnier, P., Mercier, J.L. and Han, T.L, 1986. Quaternary extension in southern Tibet: Field observations and tectonic implications, Journal of Geophysical Research: Solid Earth, 91 (B14), 13803-13872.

Avouac, J.P., Meng, L., Wei, S., Wang, T. and Ampuero, J.P., 2015. Lower edge of locked Main Himalayan Thrust unzipped by the 2015 Gorkha earthquake, Nature Geoscience, 8, 708-711. 
Bai, L., Liu, H., Ritsema, J., Mori, J., Zhang, T., Ishikawa, Y. and Li, G., 2015. Faulting structures above the Main Himalayan Thrust as shown by relocated aftershocks of the 2015 Mw7.8 Gorkha, Nepal, earthquake, Geophysical Research Letters, 43, doi:10.1002/2015GL066473.

Baur, 2007. Seismotectonics of the Himalayas and the Tibetan Plateau: Moment Tensor Analysis of Regional Seismograms, Oregon State University, p.298.

Bettinelli, P., Avouac, J.P., Flouzat, M., Jouanne, F., Bollinger, L., Willis, P. and Chitrakar, G.R., 2006. Plate motion of India and interseismic strain in Nepal Himalaya from GPS and DORIS measurements, Journal of Geodesy, 80, 567-589, doi:10.1007/s00190-006-0030-3.

Bettinelli, P., Avouac, J.P., Flouzat, M., Bollinger, L., Ramillien G., Rajaure S. and Sapkota S., 2008. Seasonal variations of seismicity and geodetic strain in the Himalaya induced by surface hydrology, Earth and Planetary Science Letters, 266, 332-344, doi:10.1016/j.epsl.2007.11.02110.

Béjar-Pizzarro, M., Carrizo, D., Socquet, A., Armijo, R., Barrientos, S., Bondoux, F., Bonvalot, S., Campos, J., Comte, D., de Chabalier, J.B., Charade, O., Delorme, A., Gabalda, G., Galetzka, J., Genricj, J., Nercessian, A., Olcay, M., Ortega, F., Ortega, I., Remy, O., Ruegg, J.C., Simons, M., Valderas, C. and Vigny, C., 2010. Asperities and barriers on the seismogenic zone in North Chile: state-of-the-art after the 2007 Mw 7.7 Tocopilla earthquake inferred by GPS and InSAR data, Geophysical Journal International, 183, 390-406, doi: 10.1111/j.1365246X.2010.04748.x.

Bollinger, L., Avouac, J.P., Cattin, R. and Pandey, M.R., 2004a. Stress buildup in the Himalaya, Journal of Geophysical Research, 109, B11405, doi:10.1029/2003JB002911. 
504

505

506

507

508

509

510

511

512

Bollinger, L., Avouac, J.P., Beyssac, O., Catlos, E.J., Harrison, T.M., Grove, M., Goffé, B. and Sapkota, S., 2004b. Thermal structure and exhumation history of the Lesser Himalaya in central Nepal, Tectonics, 23, TC5015, doi:10.1029/2003TC001564.

Bollinger, L., Perrier, F., Avouac, J.P., Sapkota, S., Gautam, U, and Tiwari, D.R., 2007. Seasonal modulation of seismicity in the Himalaya of Nepal, Geophysical Research Letters, 34, L08304, doi:10.1029/2006GL029192.

Bollinger, L., Tapponnier, P., Sapkota, S.N. and Klinger, Y., 2016. Slip deficit in central Nepal: omen for a repeat of the $1344 \mathrm{AD}$ earthquake?, Earth, Planets and Space, 68:12, doi:10.1186/s40623-016-0389-1.

Burtin, A., 2005. Seismotectonics of the Himalayan Arc from Regional Seismogram Moment Tensor Inversion, Internship report, Oregon State University.

Burtin, A., Bollinger, L., Vergne, J., Cattin R. and Nábělek J. L., 2008. Spectral analysis of seismic noise induced by rivers: A new tool to monitor spatiotemporal changes in stream hydrodynamics, Journal of Geophysical Research, 113, B05301, doi:10.1029/2007JB005034.

Cattin, R. and Avouac, J.P., 2000. Modeling mountain building and seismic cycle in the Himalaya of Nepal, Journal of Geophysical Research, 105(B6), 13389-13407.

Chanard, K., Avouac, J. P., Ramillien G. and Genrich J., 2014. Modeling deformation induced by seasonal variations of continental water in the Himalaya region: Sensitivity to Earth elastic structure, Journal of Geophysical Research: Solid Earth, 119, doi:10.1002/2013JB010451.

Collot, J. Y., Marcaillou, B., Sage, F., Michaud, F., Agudelo, W., Charvis, P., Graindorge, D., Gutscher, M-A. and Spence, G., 2004. Are rupture zone limits of great subduction earthquakes controlled by upper plate structures? Evidence from multichannel seismic 

of Geophysical Research: Solid Earth, 109, B11103.

528 Nature, 305, pp.621-623. subduction interface, Science, 292(5521), 1525-1528. Research Letters, 43, doi: 10.1002/2016GL068083. 10.1002/2015GL064587. 10.1002/2015GL066044.

reflection data acquired across the northern Ecuador-southwest Colombia margin, Journal

Das, S. and Scholz, C.H., 1983. Why large earthquakes do not nucleate at shallow depths,

Dragert, H., Wang, K. and James, T. S., 2001. A silent slip event on the deeper Cascadia

Duputel, Z., Vergne, J., Rivera, L., Wittlinger, G., Farra, V. and Hetényi, G., 2016. The 2015 Gorkha earthquake: A large event illuminating the Main Himalayan Thrust fault, Geophysical

Elliott, J.R., Jolivet, R., Gonzalez, P.J., Avouac, J.P., Hollingsworth, J., Searle, M.P. and Stevens, V.L., 2016. Himalayan megathrust geometry and relation to topography revealed by Gorkha earthquake, Nature geoscience, 9, doi:10.1038/NGE02623.

Fan, W. and Shearer P.M., 2015. Detailed rupture imaging of the 25 April 2015 Nepal earthquake using teleseismic P waves, Geophysical Research Letters, 42, 5744-5752, doi:

Grandin, R., Doin, M-P., Bollinger, L., Pinel-Puyssegur, B., Ducret, G., Jolivet, R. and Sapkota, S.N., 2012. Long-term growth of the Himalaya inferred from interseismic InSAR measurement, Geology, 40, 12, 1059-1062, doi:10.1130/G33154.1.

Grandin, R., Vallée, M., Satriano, C., Lacassin, R., Klinger, Y., Simoes, M., and Bollinger, L., 2015. Rupture process of the $M w=7.92015$ Gorkha earthquake (Nepal): insights into Himalayan megathrust segmentation, Geophysical Research Letters, 42, doi: 
548 Haines, S.S., Klemperer, S.L., Brown, L., Jingru, G., Mechie, J., Meissner, R., Ross, A. and 549 Wenjin, Z., 2003. INDEPTH III seismic data: From surface observations to deep crustal 550 processes in Tibet, Tectonics, 22(8), 1001.

551 Huc, M., Hassani, R., and Chéry, J., 1998. Large earthquake nucleation associated with stress exchange between middle and upper crust, Geophysical Research Letters, 25 (4), 551-554.

553

554

Holtkamp, S. G. and Brudzinski, M. R., 2011. Earthquake swarms in circum-Pacific subduction zones, Earth and Planetary Science Letters, 305(1), 215-225.

Holtkamp, S. G., Pritchard, M. E. and Lohman, R. B., 2011. Earthquake swarms in south America, Geophysical Journal International, 187(1), 128-146.

Jackson, M., and Bilham, R., 1994. Constraints on Himalayan deformation inferred from vertical velocity fields in Nepal and Tibet, Journal of Geophysical Research: Solid Earth, 99(B7), 13897-13912.

Jouanne, F., Mugnier, J.L., Gamond, J.F., Le Fort, P., Pandey, M.R., Bollinger, L., Flouzat, M. and Avouac, J.P., 2004. Current shortening across the Himalayas of Nepal, Geophysical Journal International, 157, 1-14, doi: 10.1111/j.1365-246X.2004.02180.x.

Khanal, S. and Robinson, D.M., 2013. Upper crustal shortening and forward modeling of the Himalayan thrust belt along the Budhi-Gandaki River, central Nepal, International Journal of Earth Science (Geol Rundsch), 102, 1871-1891.

Kobayashi, T., Morishita, Y. and Yarai, H., 2015. Detailed crustal deformation and fault rupture of the 2015 Gorkha earthquake, Nepal, revealed from ScanSAR-based interferograms of ALOS-2, Earth, Planets and Space, 67, 201, doi: 10.1186/s40623-015-0359z. 
570 Kumahara, Y., Chamlagain, D., Upreti, B. N., 2016. Geomorphic features of active faults 571 around the Kathmandu Valley, Nepal, and no evidence of surface rupture associated with 572 the 2015 Gorkha earthquake along the faults, Earth, Planets and Space, 68(1), 1-8.

573 Métois, M., Socquet, A. and Vigny, C., 2012. Interseismic coupling, segmentation and 574 mechanical behavior of the central Chile subduction zone, Journal of Geophysical Research, 575 117, B03406, doi:10.1029/2011JB00736.

576 Murphy, M. A., Taylor, M. H., Gosse, J., Silver, C. R. P., Whipp, D. M. and Beaumont, C., 2014. 577 Limit of strain partitioning in the Himalaya marked by large earthquakes in western Nepal, $578 \quad$ Nature Geoscience, 7(1), 38-42.

579 Nábelek, J., 1984. Determination of earthquake source parameters from inversion of body 580 waves. Ph. D. thesis, Massachusetts Institute of Technology, Cambridge, MA.

Nábelek, J. and Xia, G., 1995. Moment-tensor analysis using regional data: Application to the 25 March, 1993, Scotts Mills, Oregon, earthquake, Geophysical Research Letters, 22(1), 13583 16.

Nabelek, J., Hetényi, G., Vergne, J., Sapkota, S.N., Kafle, B., Jiang, M., Su, H., Chen, J., Huang, B-S. and Hi-CLIMB team, 2009. Underplating in the Himalaya-Tibet Collision Zone Revealed by the Hi-CLIMB Experiment, Science, 325, 1371-1374.

587 Nakata, T., 1989. Active faults of the Himalaya of India and Nepal, Geological Society of 588 America Special Papers, 232, 243-264. 
591

592

593

594

595

596

597

598

599

600

601

602

603

604

605

606

607

608

609

610

Pandey, M.R., Tandukar, R.P., Avouac, J.P., Lavé, J. and Massot, J.P., 1995. Interseismic strain accumulation on the Himalayan Crustal Ramp (Nepal), Geophysical Research Letters, 22, 751-754.

Pandey, M.R., Tandukar, R.P., Avouac, J.P., Vergne, J. and Héritier, T., 1999. Seismotectonics of the Nepal Himalayas from a local seismic network, Journal of Asian Earth Sciences., 17(56), 703-712.

Pearson, O.N. and DeCelles, P.G., 2005. Structural geology and regional tectonic significance of the Ramgarh thrust, Himalayan fold-thrust belt of Nepal, Tectonics, 24, TC4008, doi: 10/1029/2003TC001617.

Robinson, D.M., DeCelles, P.G., Patchett, P.J. and Garzione, C.N, 2001. The kinematic evolution of the Nepalese Himalaya interpreted from $\mathrm{Nd}$ isotopes, Earth and Planetary Science Letters, 192, 4, 507-521, doi:10.1016/S0012-821X(01)00451-4.

Sapkota S.N. ,2011. Surface rupture of 1934 Bihar-Nepal earthquake: implications for seismic hazard in Nepal Himalaya, Ph.D thesis, Institut de Physique du Globe de Paris,France. pp 2292.

Saul, J., Kumar, M.R. and Sarkar D., 2000. Lithospheric and upper mantle structure of the Indian shield, from receiver functions, Geophysical Research Letters, 27, 2357-2360.

Schmidt, D. A. and Gao, H., 2010. Source parameters and time-dependent slip distributions of slow slip events on the Cascadia subduction zone from 1998 to 2008, Journal of Geophysical Research: Solid Earth, 115, B00A18, doi:10.1029/2008JB006045. 
611

612

613

Schulte-Pelkum, V., Monsalve, G., Sheehan, A., Pandey, M.R., Sapkota, S., Bilham, R. and Wu, F., 2005. Imaging the Indian subcontinent beneath the Himalaya, Nature Letters, 435, doi:10.1038/nature03678.

Schwartz, S. Y., Dewey, J. W. and Lay, T. 1989. Influence of fault plane heterogeneity on the seismic behavior in the southern Kurile Islands Arc, Journal of Geophysical Research: Solid Earth, 94(B5), 5637-5649.

Schwartz, S. Y. and Rokosky, J. M., 2007. Slow slip events and seismic tremor at circum-Pacific subduction zones, Reviews of Geophysics, 45(3).

Shrestha, A.B., Wake, C.P., Dibb, J.E, Mayewski, P.A., 2000. Precipitation fluctuations in Nepal Himalaya and its vicinity and relationship with some large scale climatological parameters, International Journal of Climatology, 20, 317 - 327.

Souloumiac, P., Leroy, Y.M., Maillot, B. and Krabbenhoft, K., 2009. Predicting stress distributions in fold-and-thrust belts and accretionary wedges by optimization, Journal of Geophysical Research, 114, B09404, doi: 10.1029/2008JB005986.

Stevens,V.L. and J.P.Avouac, 2015. Interseismic coupling on the main Himalayan thrust, Geophysical Research Letters, 42, 5828-5837, doi:10.1002/2015GL064845.

Szeliga, W., Melbourne, T., Santillan, M. and Miller, M., 2008. GPS constraints on 34 slow slip events within the Cascadia subduction zone, 1997-2005, Journal of Geophysical Research:

Geophysical Research, v.110, Solid Earth, 113, B04404, doi:10.1029/2007JB004948. 
630

631

632

633

634

635

636

637

638

639

640

641

642

643

644

645

646

647

648

649

650

651

Waldhauser, F. and Ellsworth, W.L., 2000. A double-difference earthquake location algorithm: method and application to the Northern Hayward Fault, California, Bulletin Seismological Society of America, 90 (6), 1353-1368.

Yatagai, A., Kamiguchi, K., Arakawa, O., Hamada, A., Yasutomi, N. and Kitoh, A., 2012.

Aphrodite. Constructing a long-term daily gridded precipitation dataset for Asia based on a dense network of rain gauges, America Meteorological Society, Q07023, doi: 10.1029/2011GC003513.

Zahradnik, J., Jansky, J. and Plicka, V., 2008. Detailed waveform inversion for Moment Tensor of $M \sim 4$ events: examples from Corinth Gulf, Greece, Bulletin of the Seismological Society of America, 98 (6), pp. 2756-2771, doi: 10.1785/0120080124.

\section{$\underline{\text { Table caption }}$}

Table 1. Description of the main shocks of the three swarms of 1997. Origin time and epicentral location are from the NSC.

\section{Figure captions}

Figure 1. Seismicity map of Central Nepal from the National Seismological Center of Nepal (Modified from Adhikari et al., 2015). Red dots are the aftershocks of the Gorkha earthquake and the yellow dots indicate epicenters prior to the Gorkha event since 1994. The iso-slip contours of the Gorka earthquake are from Grandin et al., 2015. The black rectangle indicates the area used for Figure 2 and 4. Past earthquakes rupture areas (top right) from Bollinger et al., 2016. MFT: Main Frontal Thrust, MBT: Main Boundary Thrust, MCT: Main Central Thrust. The orange thin lines are the traces of the Southern Tibetan Grabens (Armijo et al., 1986) 
Figure 2. Cumulative number of events during the interseismic period recorded by the NSC from 1994 to 2015 in the area delimited in Figure 1. The black line corresponds to the events of magnitude $M L \geq 2.0$ scaled on the left side. The gray diamonds correspond to the events of magnitude $M L \geq 4.0$ scaled on the right side. $30 \%$ of the events of $M L \geq 4.0$ occurred in 1997 .

Figure 3. Centroid Moment Tensor solution for the Sarshin earthquake occurred on January $31^{\text {st }} 1997$. For each station, observations are shown with solid lines and synthetics with dotted lines. $\mathrm{Z}, \mathrm{R}$ and $\mathrm{T}$ are the vertical, radial and transverse components respectively. Radial components of CHTO, HYB and WUS were discarded because of the high signal-noise ratio. 1 and 0 are the weights used in the inversion.

Figure 4. Spatial distribution of the seismic episode of 1996-1999, north of Kathmandu (see Figure 1): The map shows the relocated seismicity as a function of time and magnitude of Zone 1 and 2 (zones boundary: longitude 85.4 ${ }^{\circ}$ ). The main shock corresponds to the 1997 January $31^{\text {st }} \mathrm{ML}=5.8(\mathrm{Mw} 4.8)$ earthquake with the preferred focal mechanism plane in red. The cross-sections include the relocated seismicity. $A-A^{\prime}$ and $B^{\prime}-B$ cross-sections are orientated N140 and N065, respectively. They stack seismicity located $10 \mathrm{~km}$ for A-A' and 3 $\mathrm{km}$ for $\mathrm{B}^{\prime}-\mathrm{B}$ from each side of the track. The area highlighted in light white correspond to the suspected fault segments at depth activated by the 1997 episode (see Figure 7 for interpretation). The intersection between $A-A^{\prime}$ and $B-B^{\prime}$ cross-sections are indicated with a black cross. The green, blue and pink-brown lines at the bottom of the map are western, central and eastern respectively used in Figure 5.

Figure 5. Time sequence of the seismicity north of Kathmandu. The zones are indicated at the bottom of the map in Figure 4. The Sarshin earthquake is indicated by the yellow star. The red dashed line is the average rate of seismicity (108 events per year). 
Figure 6. Spatio-temporal variations of the seismicity. A) Normalized time sequence of the midcrustal seismicity along the MHT. The curves correspond to the three swarm areas and the yellow one to the inter-swarms area. Gray shadow zone is the time covered in the map. B) Midcrustal seismicity for the period 1996-1997 in yellow, swarm seismicity in red. Orange circles are the Southern Tibetan Grabens north of the swarms.

Figure 7. Schematic evolution of the stress field and structure activation. A) Variation of shear stress and normal stress associated with a transient slip event on the Main Himalayan Thrust in a region with midcrustal tear faults and southern Tibetan grabens. The initial state is shown in black and is assumed tangent to the failure envelope represented by the straight line. 1, 2, and 3 refer to the different areas indicated in B and C. In area 1, s1 and s3 are horizontal, increasing and decreasing respectively, promoting failure. In area 2, s1 is horizontal, striking about north-south and increasing during interseismic deformation and transient slip events, promoting failure. In area 3, s3 is horizontal, striking approximately east-west and decreasing during interseismic deformation, promoting failure. B) and C) Kinematical evolution north of Kathmandu in 1996-1997; orange surface corresponds to the area with a coupling $>50-80 \%$ depending on source (Ader et al., 2012; Grandin et al., 2015). B) Static stress change induced by slip on the tear fault is schematized by Coulomb stress lobes, respectively blue and red for DCFF $<0$ and $>0$. Dotted lines and filled areas correspond respectively to the DCFF calculated for receiver faults with the backthrust and the thrust orientation (more information in Table S1, Table S2, and Figure S8 to S11). C) Activation of the backthrust (in green) and the thrust fault (in salmon) as a consequence of static stress change induced by the tear fault (B). D) Schematic three dimensional block, with vertical exaggeration, of the MHT with the backthrust (green) and the tear fault (purple). Colors on the MHT correspond to the coupling: red: total coupling $(>50-80 \%)$, orange: transition zone 
699 (60\%-40\%), Yellow: completely decoupled (0\%) (Ader et al., 2012; Grandin et al., 2015).

700 White arrows show the kinematics of the structures.

701

702

703 
1 Title: Lateral structure variations and transient swarm revealed by seismicity along the

2 Main Himalayan Thrust North of Kathmandu

3 Authors: R. Hoste-Colomer ${ }^{(1)(2)}$, L. Bollinger ${ }^{(1)}$, H. Lyon-Caen ${ }^{(2)}$, A. Burtin ${ }^{(3)}$, L.B. Adhikari ${ }^{(4)}$

(1) CEA, DAM, DIF, F-91297 Arpajon, France.

(2) Laboratoire de Géologie, Ecole Normale Supérieure/CNRS UMR 8538, PSL Research University, Paris 75005, France.

(3) Institut de Physique du Globe de Paris, Sorbonne Paris Cité, Université Paris Diderot, UMR 7154 CNRS, Paris, France.

(4) Department of Mines and Geology, National Seismological Center, Kathmandu, Nepal.

Corresponding Author: Roser Hoste-Colomer

Phone: +33 169265463

e-mail: roser.hoste-colomer@cea.fr

\section{ABSTRACT}

The midcrustal seismicity along the Main Himalayan Thrust in Nepal presents lateral variations along the rupture of the 2015 Gorkha earthquake. In order to resolve these variations, we relocate the seismicity north of Kathmandu, during a period well covered by the Nepal National Seismological Network, using a double-difference algorithm. The 550 relocated events highlight a complex pattern of clustered seismicity within the unstablestable transition zone. Part of the seismicity is densely clustered on a southward dipping plane which ruptured on January $31^{\text {st }} 1997(\mathrm{ML}=5.8)$, activating a backthrust with a geometry consistent with the centroid moment tensor of this event calculated in this study. 

35 44

At its eastern end, the midcrustal cluster is offset by $20 \mathrm{~km}$ to the south suggesting the presence of a tear fault. The analysis of the time sequence allows constraining a scenario involving stress transfer between these local midcrustal structures, beginning more than one month before the 1997 main shock. The temporal evolution of the seismicity is strikingly similar for two other transient seismic swarm episodes which developed hundreds of kilometers apart along the Main Himalayan Thrust at the same time. The local stress field appears responsible for the higher sensitivity of these regions to subtle strain transients developing along the Main Himalayan Thrust.

Key words: seismicity, Main Himalayan Thrust, fault segmentation, relative relocation.

(1) 36

.

38

39

40

\section{1} 2 43 


\section{Introduction}

Along-strike variations of seismic activity on a fault can result from lateral variations in the geometry of the locked fault zone, spatial heterogeneity in frictional parameters or from unsteady loading during the interseismic period. Variations in seismicity rates along the downdip end of a locked megathrust may reveal that the structure is segmented, and these segment boundaries may correspond to the barriers that delimit major seismic ruptures (e.g. Schwartz et al., 1989; Collot et al., 2004; Métois et al., 2012; Holtkamp et al., 2011; Holtkamp and Brudzinski, 2011). The Main Himalayan Thrust (MHT) fault in Nepal qualifies as one interesting fault to document in terms of seismicity variations given its seismogenic potential and the possible control of the coseismic ruptures by persistent structural features (e.g. Grandin et al., 2015). Indeed, despite the apparent homogeneity of the stress build up revealed by geodesy (Ader et al., 2012; Stevens and Avouac, 2015) significant variations of the seismic rate have been reported along strike (Pandey et al., 1999). Some of the variations in seismic rate are persistent in time and might reveal lateral heterogeneity in terms of seismic coupling and/or tectonic structures along strike of the MHT. Others are temporary, related to transient episodes including swarm activity or mainshock-aftershock sequences.

On April 252015 at 11 h56 Nepal Standard Time (06h11 UTC), the Mw 7.8 Gorkha earthquake ruptured a $120 \mathrm{~km}$-long and $35-50 \mathrm{~km}$ wide fault segment of the MHT (e.g., Avouac et al., 2015; Grandin et al., 2015; Kobayashi et al., 2015; Elliott et al., 2016)(Figure 1), abutting the great M8.2 1934 earthquake rupture. The propagation of the rupture and the slip along the fault plane were heterogeneous, leading some authors to suggest possible 
along strike variations of the structure at depth (Grandin et al., 2015, Fan and Shearer, 2015).

The aftershocks near the trace of the rupture in the vicinity of Kathmandu are heterogeneously distributed (Adhikari et al., 2015; Bai et al., 2015). Some aftershocks are clustered under Kathmandu valley, a place where no seismicity has been observed during the interseismic period (Figure 1). In the meantime, north of the Nepalese capital, the aftershocks epicenters coincide with the location of the midcrustal interseismic cluster (10$20 \mathrm{~km}$ depth) (Figure1). The heterogeneous distribution of the Gorkha earthquake aftershocks and the seismicity during interseismic period north of Kathmandu could be due to structural complexities or a transient event. The goal of our study is to use small earthquakes prior to the 2015 Gorkha event to resolve structural and frictional characteristics that might control the rupture parameters of the main shock.

In order to test such a hypothesis, we analyze the spatio-temporal variations of the seismicity during the interseismic period north of Kathmandu, a region well covered by the Nepalese national seismological network. We first relocate the seismic events using a double-difference algorithm (Waldhauser and Ellsworth, 2000) and perform a Centroid Moment Tensor inversion of the largest instrumentally recorded event in the region, $M L=5.8$ on January $31^{\text {st }} 1997$. We then interpret the spatial pattern of seismicity in terms of geological structures at depth, and finally focus on the temporal variation of the seismicity rate along this structure.

\section{Data description}

\subsection{Regional Network}


The seismicity of central and eastern Nepal has been continuously monitored since the 1990s by the National Seismological Centre of Nepal (NSC) with a national network composed of 21 short period vertical component seismic stations. Among them 12 high gain stations have been operational since 1994 in central and eastern Nepal providing a completeness of the seismic catalogue for that region around local magnitude $\mathrm{ML}=2.0$ (Pandey et al., 1999). Their records are processed using Jade-Onyx acquisition-treatment software in which a 1D velocity model is used to locate earthquakes using the phases picked manually at NSC (Pandey, 1985; Pandey et al., 1995, Adhikari et al., 2015). A complementary network of 3 stations was deployed temporarily, from July 1995 to December 1996 . The addition of these stations facilitated improved locations for the small earthquakes generated at midcrustal depths below the front of the high topography (Cattin and Avouac, 2000) in the vicinity of the Main Himalayan shear zone (Nabelek et al., 2009).

\subsection{Earthquake catalogue}

North of Kathmandu, the interseismic activity appears concentrated at midcrustal depths within a permanent seismic cluster (Pandey et al., 1995; Cattin and Avouac, 2000) (Figure 1) modulated by a few transient seismicity bursts (Figure 2). The most important seismicity burst was recorded in 1997. Indeed, $30 \%$ of the $M L>=4.0$ events of the catalogue in this region occurred in that year (Figure 2). The sequence culminated after the occurrence of the "Sarshin earthquake" an ML=5.8 event which happened on January $31^{\text {st }} 1997$ (Table 1), an event preceded 3 hours before by a foreshock of ML 5.1. This event resulted in a maximum shaking intensity of MMI VII and was felt in Kathmandu $40 \mathrm{~km}$ SE from its epicenter. It caused significant impact (MMI VI) over a region $1800 \mathrm{~km}^{2}$ in size (Sapkota, 2011). Given its magnitude, this event was also recorded at teleseismic distances by international 
112 institutions, which assigned a body-wave magnitude ( $\mathrm{mb}$ ) around 5.2 and depths between

11317 and $23 \mathrm{Km}$ (Table 1).

114 The Sarshin earthquake was followed by more than 160 aftershocks in a region spanning 50

$115 \times 30 \mathrm{~km}^{2}$, a surface significantly larger than the expected rupture extension. The orientation

116 of the seismic cluster based on NSC locations is unclear and we expect that relocated

117 aftershocks will help to constrain the geometry of the structure activated by the Sarshin 118 earthquake.

119 3. Method

\section{$120 \quad$ 3.1. Centroid Moment Tensor at regional scale}

121 Seismic data of the 1997 Sarshin earthquake recorded by stations at distances up to $1700 \mathrm{~km}$

122 and of good quality are used to calculate a Centroid Moment Tensor. This includes data from

123 stations LSA (Tibetan plateau), HYB (central India), WUS (northern China) and CHTO

124 (Thailand) (Figure 3).

125 The centroid moment tensor solution is retrieved from the inversion of regional long-period

126 seismic waves (40-100s). The procedure is taken from Nábelek (1984) and is adapted to a

127 low-frequency inversion (Nábelek and Xia, 1995). For the centroid moment tensor inversion,

128 a 1-D velocity structure should be chosen to compute synthetic Green's functions and model

129 the observed waveforms at seismic stations. Processing a large number of events (29

130 earthquakes in (Burtin, 2005) and 107 earthquakes in (Baur, 2007) in the Himalaya and

131 Tibetan Plateau regions) we failed to correctly invert the seismic waveforms at stations with

132 a single velocity model. Seismic signals from sources occurring along the Himalayan arc were

133 recorded at stations located around the Tibetan plateau and the India plate. Therefore,

134 velocity structures through which seismic waves travel can drastically change. For instance 
when a velocity model with a Moho depth fixed at $35 \mathrm{~km}$ (ex. India path) is used, the modeled waveforms for northern Tibetan stations will systematically arrive sooner than the observed ones. To overcome this issue, each ray path is associated with a specific 1-D structure. For the Indian station HYB, the model is from Saul et al., (2000) with a Moho depth at $35 \mathrm{~km}$. For the Tibetan station LSA and northern China station WUS, the model is modified from Haines et al., (2003) with a Moho depth at $65 \mathrm{~km}$. In this latter model, we had to remove the $5 \mathrm{~km}$ thick sedimentary layer because otherwise the synthetic inverted seismic waves were delayed too much. Finally, the model for the Thai station CHTO was set to an intermediate model between the Indian and Tibetan models with a Moho depth at 45 $\mathrm{km}$. These velocity models were tested using a trial and error procedure on the 29 focal mechanisms studied (Burtin, 2005); we retained those models that resulted in synthetics that best matched the observed seismic data (Figure 3) - See Burtin, 2005 for further information. Furthermore, for each earthquake analyzed in Burtin (2005), including the Sarshin earthquake, the centroid moment tensor source depth was constrained through a grid search algorithm that minimized the waveform misfit, using at first a coarse step size (10 $\mathrm{km})$ followed by a finer step size $(1 \mathrm{~km})$.

\subsection{Relative relocation at local scale}

We calculate relocations using the double-difference algorithm HypoDD (Waldhauser and Ellsworth, 2000) for the seismicity clustered north of Kathmandu, in the trace of the Gorkha earthquake. We use data from the NSC bulletin for the period 1996-1999 and the whole bulletin from the temporary experiment of 1995-1996. Relative locations are resolved by solving an inverse problem using a damped least-square technique, minimizing the residuals between observed and calculated phase delay times between a pair of adjacent earthquakes 
recorded at common stations. This procedure reduces the biases induced by velocity model errors along the paths from hypocenters to seismic stations. The velocity model considered hereafter is the 1-D model of Pandey (1985) with a Vp/Vs of 1.73 . We initially attribute to each seismic event the origin time and hypocenter of the NSC seismic bulletin. We also allocate location errors corresponding to the average of the longitudinal and latitudinal uncertainties as well as depth uncertainties documented in the bulletin. Undetermined depths in the database are fixed to 0 . The second set of inputs include the arrival times of $P$ and $\mathrm{S}$ phase arriving at a station for a given event. The weight for the $\mathrm{P}$ phases is fixed to 1 and for the S phases to 0.3 .

Given the very high density of events located immediately in the vicinity of the Sarshin earthquake, compared to the more diffuse spatial and temporal pattern of the seismicity elsewhere, we divide the catalogue of events in two, a western and an eastern region (respectively zones 1 and 2 hereafter) separated at 85.4E (Figure S1 and S3). This division will enable us to better optimize the relocation process.

We select pairs of phases at every station considering (1) a maximal separation between hypocenters of $20 \mathrm{~km}$ and (2) a minimum number of links between two neighbor events of 8 for Zone 1 and of 4 for Zone 2.

The relocation is performed in both cases with $\mathrm{P}$ and $\mathrm{S}$ phases when available and with three sets of iterations taking into account the seismic bulletin parameters. We set the damping at 20 in a LSQR inversion. The first set iterates four times using only $P$ waves. The second set iterates also four times with $\mathrm{P}$ and $\mathrm{S}$ waves. The third set iterates 8 times taking into account $\mathrm{P}$ and $\mathrm{S}$ waves, limiting the residuals to 5 seconds and the maximum distance between linked pairs to $10 \mathrm{~km}$. The relocation of Zone 1 considers 8 as the minimum number of links per pair 
to form a continuous cluster. There is no clustering a priori parameter for the relocation of Zone 2.

We tested the most influential parameters for both the pair-phase selection and the relocation process. In the pair-phase selection, we tested values at 4,8 , and 12 for the minimum number of links between two neighbor events. We also tested maximum separation between hypocenters at 20 and $50 \mathrm{~km}$. The number of pair-phases created increase considering either a larger number of minimum links per pair or a larger maximum separation distance between hypocenters, however there are more events weakly linked. The minimum number of links between two neighbor events tested changes in Zone 1 and 2 because of the density of events. We also tested various numbers of iterations ( 4 and 8 for each set) in the relocation process. The RMS misfit decreases for the first two sets until it stabilizes after 4 iterations. The solution becomes unstable with 8 iterations, resulting in a centroid shift and in an unstable RMS misfit. In the third step, 8 iterations are needed to stabilize the RMS misfit. Geometrically, the relative relocations were similar for any iteration scheme.

The tests results support the parameters we chose for Zone 1 and 2.

\section{4- Results}

In Zone 1 (Figure 4), the seismic bulletin includes 230 events with 2408 phases from which 20140 P-phases pairs and 12469 S-phase pairs are found. 80\% of P-phase pairs and $84 \%$ of Sphase pairs are selected. The event pairs have an average of 10 links with an average offset of $6.04 \mathrm{~km}$. After event pair selection, 167 events are successfully relocated, with less than $1500 \mathrm{~m}$ of 2-sigma-relative location errors in $x, y, z$ and a RMS misfit reduction of $60 \%$ (Figure S2, S3, S5, and S6). 
The seismic bulletin covering Zone 2 (Figure 4) includes 548 events with 4886 phases from which 45938 P-phase and 39002 S-phase pairs are determined. Respectively, 49\% and 45\% of P- and S-phase pairs are selected. The event pairs have an average of 6 links with an average offset of $6.9 \mathrm{~km} .477$ events are selected, from which 384 events are successfully relocated with less than 100 m of 2 -sigma-relative location errors in $x, y, z$. The RMS misfit reduction, following the integration of the phases picked at the temporary 3 component stations, is close to $90 \%$ (Figure S2, S3, S4, S5, S6, and S7).

The relocation of Zone 1 and Zone 2 seismicity indicates the presence of two separate clusters during the 1997 seismic episode (Figure 4). The westernmost seismic cluster is located between $85.3^{\circ}$ and $85.4^{\circ}$, covering an area of $7 \times 11 \mathrm{~km}^{2}$ (Figure 4, map), just above the January $31^{\text {st }}$ Sarshin earthquake hypocenter (Figure 4, cross-section). The visual inspection of $3 \mathrm{D}$ plots shows that the seismicity lies on a plane that strikes $\mathrm{N} 050 \pm 20 \mathrm{E}$ dipping steeply southeast $\left(70-80^{\circ}\right)$. The other seismic cluster is smaller $\left(6 \times 8 \mathrm{Km}^{2}\right)$ and is located between $85.4^{\circ}$ and $85.5^{\circ}$. It describes an almost vertical plane striking $\mathrm{N} 155 \pm 20 \mathrm{E}$ (Figure 4). No large event is associated with this cluster. The remaining relocated seismic events do not show a particular geometry. Most of them are located in a $10 \mathrm{~km}$-wide band east of $85.5^{\circ}$.

The centroid moment tensor solution for the January $31^{\text {st }}$ Sarshin earthquake indicates a best centroid depth at $17 \mathrm{~km}$ and a reverse motion with a slight strike-slip component. One nodal plane (NP1) strikes N075 and dips $85^{\circ} \mathrm{SE}$, and the second (NP2) strikes N152 and dips $24^{\circ} \mathrm{NE}$. Although it is difficult to quantify uncertainties on the centroid moment tensor solution, the azimuthal coverage being decent and the changes in centroid moment tensor being small in the vicinity of the best depth, we consider the uncertainties to be moderate 

in the inversions. The NP1 plane is the closest to the plane defined by the relocated aftershocks of the Sarshin earthquake. The moment magnitude obtained is $\mathrm{Mw}=4.8$.

The depths of the relocated events range from 15 to $26 \mathrm{~km}$ in the western cluster, with the main shock at $24 \mathrm{~km}$ depth which is slightly deeper than previous determinations (Table 1 ).

232 NSC gives a hypocenter at $20.3 \mathrm{~km}$ while the centroid moment tensor centroid depth is at 17 $\mathrm{km}$. Although the relocation allows us to place constraints on the relative positions of hypocenters leading to a fairly well defined geometry for the cluster, the centroid depth of the cluster $(\sim 22 \mathrm{~km})$ is less well constrained as the closest station that recorded these events is located at $\sim 25 \mathrm{~km}$, and thus the centroid could move by a few kilometers. Both hypocenter depths and centroid moment tensor centroid depths being within $+/-5 \mathrm{~km}$, we think the differences may not be significant. In addition, as most crustal earthquakes nucleate at depth and propagate towards the surface (e.g., Das and Scholz, 1983; Huc et al., 1998), we expect the hypocenter depth of the mainshock to be larger than its centroid

241 moment tensor depth. This will be particularly true if the co-seismic slip is small and the 242 ruptured area large for a Mw4.8 event. Indeed, the source of a Mw4.8 can be either $2 \times 2 \mathrm{~km}^{2}$ 243 with $10 \mathrm{~cm}$ of slip or $5 \times 5 \mathrm{~km}^{2}$ with $2 \mathrm{~cm}$ of slip.

\section{5-Interpretation}

\section{Spatial distribution of the Sarshin Swarm}

246 Most of the 1996-2000 Sarshin Swarm seismicity is located at midcrustal depths, with centroid depths at 22 and $15 \mathrm{~km}$ respectively for the two clusters (Figure 4). These depths roughly correspond to the depth of the Main Himalayan shear zone, as interpreted on 
images obtained along profiles based on receiver function analysis (Schulte-Pelkum et al., 2005; Nabelek et al., 2009; Duputel et al., 2016).

251

The westernmost cluster develops after the main shock of the Sarshin earthquake over a $7 \mathrm{x}$ $11 \mathrm{~km}^{2}$ region. Given the geometry of the cluster and the fault plane solution parameters of its main shock, the January $31^{\text {st }} 1997$ Sarshin earthquake, we associate this seismic swarm to the activation of a NE-SW backthrust, steeply dipping to the southeast. Assuming that the aftershock distribution corresponds to the maximum extent of the fault segment ruptured by the main shock, a $\mathrm{Mw} 4.8\left(\mathrm{MO}=2.3^{*} 10^{16} \mathrm{Nm}\right.$ deduced from the centroid moment tensor determination), and assuming a shear modulus of 32GPa we obtain an average minimum slip of $1 \mathrm{~cm}$. Considering that aftershocks may more likely extend beyond the edges of the ruptured plane, its surface is likely overestimated. A surface overestimation by $100 \%$ will lead to doubling the average slip, at $2 \mathrm{~cm}$. This amount of slip at depth induces infra-mm displacements at the surface GPS sites around, values below the resolution capacity of the campaign GPS available at that time (Jouanne et al., 2004).

A rupture on a steep south-eastward dipping - northwestward verging thrust at mid-crustal depths below the front of the high topography may correspond either to the activation of (a) a fault segment at the forelimb of the lesser Himalayan duplex (e.g. Pearson and DeCelles, 2005; Khanal and Robinson, 2013), or (b) a local shear zone within the hinge above the flatdecollement/ramp, as predicted by mechanical models (Souloumiac et al., 2009) (Figure 7D). We prefer the latter interpretation, as the depth seems more consistent with the downdip end of a midcrustal ramp than the passive roof-thrust of the duplex.

The relocated seismicity appears offset by $20 \mathrm{~km}$ from west to east, describing an eastward right-stepping strand. Note that this step is not an artifact due to the location of the 
boundary between the two zones considered in the relocation process: alternative

273

relocations considering only one zone, keeping the same relocation parameters, produced similar spatial patterns, with the seismic cluster stepping to the south in this area. This offset could be explained by the presence of a tear fault between two ramps or structural discontinuities within the Main Himalayan shear zone such as a stepover of the fault. We prefer the former hypothesis given the absence of overlapping seismicity along strike. In addition, the vertical NW-SE plane described by the second cluster $\left(85.4^{\circ}\right.$ and $\left.85.5^{\circ}\right)$ identified in the relocation results is consistent with tear faulting although we could not compute any fault plane solution to prove this. Such tear faults are required because of the topology of the MHT flat/ramp system and its lateral variations (Figure 7). The right lateral tear fault suspected to develop at depth within the trace of the second cluster is aligned with an active dextral fault system reaching the surface along the $20 \mathrm{~km}$-long NNW-SSE Jhiku Khola fault (Kumahara et al., 2016).

We propose that the backthrust and tear fault activated during the 1997 seismic episode, and in a more general way every significant variation of the structure at depth along the $\mathrm{MHT}$, might influence its behavior. It could affect the propagation of the co-seismic rupture (e.g. Béjar-Pizarro et al., 2010), influencing the co- and post-seismic slip distribution as well as the location of the aftershocks. Note that the structure we studied is located in between two patches of maximum slip of the Gorkha earthquake proposed by some authors (e.g. Avouac et al., 2015; Grandin et al., 2015) (Figure 1).

\section{$\underline{\text { Temporal distribution of the seismicity at local and regional scales }}$}


The time structure of a seismic episode gives a dynamic sense and evolution of the

294

295

296

297

298

299

300

301

302

303

304

305

306

307

308

309

310

311

312

phenomenon that the spatial distribution does not. Both are essential to interpret our results.

The time structure of the seismicity in this area (Figure 4) exhibits complex variations in the period covered by our study. The seismicity rate decreases first in mid-1996 (Figure 2 and 5). This relative quiescence is difficult to ascertain, being concurrent with the monsoon arrival, a period during which the seismic noise level and therefore the completeness magnitude of the catalogue is higher than on average, a period during and slightly after which the seasonal load of the india plate has a genuine influence on the seismicity (Bollinger et al., 2007; Bettinelli et al., 2008; Burtin et al., 2008). The seismic rate remains low until December, far after the monsoon period, and is followed by a sharp increase. The seismic events are then clustered between $85.4^{\circ}$ and $85.5^{\circ}$ (Central zone in Figure 4), mostly along a $6 \mathrm{~km}$-long vertical plane oriented N155. This activity, decreasing at the beginning of 1997, is followed by the development of another cluster $15 \mathrm{~km}$ to the northwest in January (Figure 4,5 ). The swarm in the area begins before the Sarshin main shock which occurred at 20:02 (local time) on January 31st and was preceded by a ML5 and smaller events a few hours earlier. The seismic cluster that developed within the next three months within $10 \mathrm{~km}$ from the hypocenter is typical of an aftershock sequence. In the meantime, the seismicity rate east of $85.5^{\circ} \mathrm{E}$ increased significantly (Figure 5).

Surprisingly, this unusual transient seismic activity is not exceptional in the Himalaya region. Indeed, in eastern Nepal, a seismic swarm developed between 86.8 and $87^{\circ} \mathrm{E}$, generating 80 events south of Mount Everest, between November 1996 and May 1997. No main shock was detected prior to the onset of the seismic swarm but a larger shock, with a ML 5.8, occurred on the 30/12/1996 (Table 1) and was followed by aftershocks (Figure 6). In western Nepal, 
between $80.5^{\circ}$ and $81^{\circ} \mathrm{E}$, a similar swarm developed with a main shock on $05 / 01 / 1997$ of $M L=6.3$ (Table 1). The location of the seismicity in these two areas is not sufficiently resolved to perform an analysis similar to what has been done here. The time structure of these two swarms is very similar to that of Sarshin as illustrated on Figure 6.

Altogether, the 3 clusters contribute to $40 \%$ of the yearly midcrustal events detected along the front of the range in Nepal. Their cumulative along strike development accounts for $\sim 10$ $\%$ of the length of the midcrustal cluster making this event the most important seismicity burst of the interseismic period recorded by the Nepal National Seismological Network. No significant seismic rate variations were detected in between the three clusters (Figure 6).

\section{6- Discussion}

Complex spatial and temporal variations of seismicity have been revealed at local and regional scales. Locally, north of Kathmandu, the spatial distribution of the seismicity coincides with a back-thrust and a thrust segment separated by a proposed $20 \mathrm{~km}$-long tear fault. Their consecutive activation follows the development of a seismic swarm on the tear fault. The geometry of the fault system is consistent with a right lateral slip on the tear fault. This scenario is compatible with the topology of the thrust system as well as with the kinematics of the dextral NNW-SSE Jhiku Khola fault described in continuity to the south (Kumahara et al., 2016). The en-echelon segments of the MHT there are close to the unstable-stable transition zone USTZ (e.g. Jackson and Bilham, 1994; Bettinelli et al., 2006). This behavior was confirmed recently by the determination of the seismic coupling that falls there between 0.4 and 0.6 (Ader et al., 2012; Grandin et al., 2012; Stevens and Avouac, 2015).

The seismic activity in 1997 in this region could result from (1) a local unsteady loading or (2) a local strain transfer in the vicinity of the USTZ. However, rather than just a local strain 
transient, the development in 1996-97 of 2 other clusters hundreds of kilometers apart,

depicting similar temporal variations, may imply (3) a large scale unsteady loading. The unsteady loading could be due, among others, to a lithospheric response to the water mass redistribution after the monsoon or to a slow slip event. However, in 1996, the precipitation records were fairly typical (e.g., Shrestha et al., 2000; Yatagai et al., 2012). This leads us to propose that the 1997 seismic episode may be related to a slow slip event. A transient slip event with a slip amplitude of tens of centimeters is precluded due to the absence of measurable changes in the seismicity rate between the clusters (Figure 6A). Indeed, a seismicity change would likely occur after a centimetric to decimetric scale slow slip event, which would in turn release years of stress build up and therefore most probably induce years of midcrustal seismicity along strike. The lower end of the slip amplitude expected, i.e. $1 \mathrm{~cm}$, would correspond roughly to the seismic slip accommodated during the Sarshin earthquake (see previous section for estimation). In Sarshin area, such an amount of slip at midcrustal depths generates only infra-milimetrical displacements at RAMO and SYAO, regional GPS stations respectively 17 and $20 \mathrm{~km}$ from the updip-end of the ruptured fault plane. These stations were surveyed briefly in 1995 and 1998 ( 1 to 4 days/sessions). They were translated in 3 years by $19 \pm 6 \mathrm{~mm}$ and $21 \pm 7 \mathrm{~mm}$ respectively in an India fixed reference frame (Jouanne et al., 2004). The large uncertainties of the measurements preclude resolving the infra-milimetrical displacements induced by the Sarshin earthquake as well as those induced by any strain transient with similar amplitudes. We further note that the displacements uncertainties for both stations amounts to one third of the measurements, a value comparable to one year of strain above the Main Himalayan Thrust. The thrust accommodates, at depth, on average, a shortening of $18 \mathrm{~mm} / \mathrm{yr}$ (Ader et al., 2012). 
therefore seems impossible. This result is corroborated by the absence of any major change in the shortening rates estimated elsewhere in Nepal by campaign GPS data, and by the continuous DORIS time series available at Everest.

Several of the large transient events elsewhere in the world were accompanied by tremors and low frequency earthquakes (Schwartz and Rokosky, 2007). Such kinds of seismic events have not been observed in 1997 in Nepal, a period during which the continuous seismic signals recorded by National Seismological Network was not stored. Further analysis of these signals to detect tremors or low frequency earthquakes is therefore limited to the cut signals of seismic events which, according to a preliminary analysis, present a typical spectra.

Despite the lack of direct evidence that tremors and low frequency earthquakes occurred, we think the seismic catalogue contains other indirect evidences of this process.

A subtle transient slip event may generate heterogeneous seismicity along strike due to the geometry and state of stress changes along strike of the MHT. Indeed, the midcrustal seismicity under the front of the Himalayas appears sensitive to the local state of stress which depends mainly on the regional tectonic stress and the topography, through their influence on the preferred orientation of the failure planes (Bollinger et al., 2004a). In between the Main Frontal Thrust and the front of the High range, S3 and S1, the minimal and maximal principal stresses, are respectively vertical and north-south. S1 increases during interseismic deformation due to slip at depth on the $\mathrm{MHT}$, promoting failure on EW striking thrust planes (Figure 7A(area 2)). Further north, in the Southern Tibetan grabens (Figure 6B), S1 is vertical while S3 is horizontal, striking approximately east-west. S3 might decrease during interseismic deformation (Figure 7A(area 3)), since east-west extension increases in the Southern Tibetan Graben due to the divergence of thrusting along the Himalayan Arc (Bollinger et al., 2004a). This promotes failure on north-south oriented normal faults (ie: the 
southern Tibetan grabens). In between these two domains (i.e. south of the range, Tibetan Plateau: between area 2 and 3 on Figure 7A) the regional state of stress might promote the existence of NW-SE and NE-SW strike slip faults. This is valid for a range of depths in the cluster which depends on both S1 and S3 and the local non compensated topography. In this area, the intermediate stress component is vertical, while the maximum and minimum principal stresses correspond respectively to the north-south and east-west stress values (Figure $7 \mathrm{~A}($ area 1$))$. The strike slip faults in this region are very sensitive to the simultaneous N-S and E-W stress variations (Figure 7A). The lack of strike slip Centroid Moment Tensor solutions for intermediate events $(M>5.5)$ during the last decades along the Himalaya demonstrate that strike slip faulting is infrequent along strike, probably due to the restriction to a small depth range of the corresponding state of stress. Besides the presence of large scale active strike-slip faults affecting the lesser Himalayas (Nakata, 1989), interpreted as resulting from large scale strain partitioning (Nakata, 1989; Murphy et al., 2014) or from the presence and migration of lateral ramps (Bollinger et al., 2004b), few active strike-slip fault segments were described at the foot of the High range (Nakata, 1989). However, tear-faults are suspected at midcrustal depths because of the lateral variations of the midcrustal ramps along the strike of the Main Himalayan thrust (e.g. Robinson et al., 2001; Bollinger et al., 2004b; Grandin et al., 2012). Despite the publication of balanced cross sections immediately west of Sarshin area (e.g. Pearson and Decelles, 2005; Khanal and Robinson, 2013), the present-day positions of the midcrustal ramps in the vicinity of the seismic cluster studied here are still unresolved. Assuming the cluster represents the edge of the MHT locked segment (e.g. Cattin and Avouac, 2000; Bollinger et al., 2004; Ader et al., 2012, Grandin et al., 2015), a dextral NW-SE transform structure is required for the sake of geometrical continuity (Figure 4 and 5, Central zone in blue). Assuming that this swarm is 
located on such a right lateral strike slip segment, its activity in December 1996 creates static

stress changes at its extremities. It leads to the generation of 2 positive Coulomb stress variations (DeltaCFF) lobes on its NW and SE sides (while NE and SW would see a negative DeltaCFF(Figure S8 to S11 and Table S2). This static stress change scenario accounts for the generation of seismicity along the backthrust to the NW and the thrust to the SE as well as with the lack of microseismic activity along its NE and SW extremities (Figure 7B and 7C). Furthermore it is consistent with Sarshin focal mechanism depicting a NE-SW oriented fault plane solution (Figure 4).

Whether similar kinematics and mechanisms are involved in the generation of the Far western and eastern Nepal seismic swarms is unknown. Unfortunately, the seismicity in these regions cannot be analyzed with a similar relocation approach due to the less optimal geometry of the seismic network and completeness of the database. But the 3 swarms are located in similar settings, within the midcrustal cluster at similar distances from the USTZ and within the trace of southern Tibetan Grabens (Figure 6B). Another similarity is their time sequence that begins with a weak but detectable decrease of seismicity prior to the swarms' development (Figure 6A). These rate decreases begin about 6 months prior to each swarm, during the onset of the monsoon. That the higher level of seismic noise during the monsoon is responsible for the seismic rate decrease is possible (Bollinger et al., 2007), but the rate remains low after the end of the monsoon and the decrease of the seismic noise generated by landsliding and rivers (Burtin et al., 2008). An alternative interpretation could be that the seismicity was partially inhibited and then promoted due to the response of the crust to a loading/unloading of continental water (Bettinelli et al., 2008; Chanard et al., 2014) in 1996. Whatever the scenario, the simultaneous development of these swarms may have resulted from a transient slip event similar to those detected along other subduction zones (e.g. 
Cascadia, Mexico, Japan,...) with an affected area between 30 to $600 \mathrm{~km}$ along strike, and

transient slip lasting 6 days to about a year with amplitudes between $5 \mathrm{~mm}$ and $5.6 \mathrm{~cm}$ (e.g.

439 Dragert et al., 2001; Schmidt and Gao, 2010; Schwartz and Rokosky, 2007; Szeliga et al., 440 2008).

441 Such a slow slip event occurring on the Main Himalayan Thrust could play a role in the 442 seismic cycle of the locked segment of the fault. Indeed, such transient events bring the 443 locked fault zone closer to failure by several months (Dragert et al., 2001), besides the 444 interseismic loading on the fault.

\section{7- Conclusion}

The first conclusion to be drawn from this work is that the downdip end of the locked section of the Main Himalayan Thrust exhibits lateral seismicity variations that may reveal the presence of structural complexities at midcrustal depths. The right-stepping geometry of the seismicity, north of Kathmandu, is interpreted as resulting from the activation of a tear

450 fault between a backthrust and a thrust segment. This structural complexity might have influenced the slip distribution during the Gorkha earthquake rupture as revealed by a local

452 minima in the region of high slip of some published slip models. A second major conclusion 453 is that the time sequence of the seismic swarm which developed there in 1996-97 is 454 consistent with a propagation of a local strain transient, from the tear fault to the backthrust 455 and thrust. Finally, the temporal coincidence between this swarm and two others at far distances leads us to suspect the development of a larger-scale transient slip event on the 457 Main Himalayan Thrust. The local stress field appears responsible for the higher sensitivity of 458 these areas to strain transients and needs therefore to be monitored to ascertain the 459 presence of infrequent subtle slow slip events along the Himalaya. 
This project is funded by the French Agence Nationale de la Recherche (ANR-13-BS06-000601) and the Comissariat à l'Energie Atomique et aux Energies Alternatives. We thank the National Seismological Centre, Sudhir Rajaure and Soma Nath Sapkota for early exchanges on the seismic catalogue and macroseismic field of the Sarshin earthquake. The authors also thank the two anonymous reviewers and Gavin P. Hayes for their helpful comments that improved the paper.

\section{References}

Ader, T., Avouac, J.P., Liu-Zeng, J., Lyon-Caen, H., Bollinger, L., Galetzka, J., Genrich, J., Thomas, M., Chanard, K., Sapkota, S.N., Rajaure, S., Shrestha, P., Ding L. and Flouzat, M., 2012. Convergence rate across the Nepal Himalaya and interseismic coupling on the Main Himalayan Thrust: Implications for seismic hazard, Journal of Geophysical Research, 117, B04403, doi: 10.1029/2011JB009071.

Adhikari, L.B., Gautam, U.P., Koirala, B.P., Bhattarai, M., Kandel, T., Gupta, R.M., Timsina, C., Maharjan, N., Maharjan, K., Dahal, T., Hoste-Colomer, R., Cano, Y., Dandine, M., Guilhem, A., Merrer, S., Roudil, P. and Bollinger, L., 2015. The aftershock sequence of the 2015 April 25 Gorkha-Nepal earthquake, Geophysical Journal International, 203, 2119-2124, doi: 10.1093/gji/ggv412.

Armijo, R., Tapponnier, P., Mercier, J.L. and Han, T.L, 1986. Quaternary extension in southern Tibet: Field observations and tectonic implications, Journal of Geophysical Research: Solid Earth, 91 (B14), 13803-13872.

Avouac, J.P., Meng, L., Wei, S., Wang, T. and Ampuero, J.P., 2015. Lower edge of locked Main Himalayan Thrust unzipped by the 2015 Gorkha earthquake, Nature Geoscience, 8, 708-711. 
Bai, L., Liu, H., Ritsema, J., Mori, J., Zhang, T., Ishikawa, Y. and Li, G., 2015. Faulting structures above the Main Himalayan Thrust as shown by relocated aftershocks of the 2015 Mw7.8 Gorkha, Nepal, earthquake, Geophysical Research Letters, 43, doi:10.1002/2015GL066473.

Baur, 2007. Seismotectonics of the Himalayas and the Tibetan Plateau: Moment Tensor Analysis of Regional Seismograms, Oregon State University, p.298.

Bettinelli, P., Avouac, J.P., Flouzat, M., Jouanne, F., Bollinger, L., Willis, P. and Chitrakar, G.R., 2006. Plate motion of India and interseismic strain in Nepal Himalaya from GPS and DORIS measurements, Journal of Geodesy, 80, 567-589, doi:10.1007/s00190-006-0030-3.

Bettinelli, P., Avouac, J.P., Flouzat, M., Bollinger, L., Ramillien G., Rajaure S. and Sapkota S., 2008. Seasonal variations of seismicity and geodetic strain in the Himalaya induced by surface hydrology, Earth and Planetary Science Letters, 266, 332-344, doi:10.1016/j.epsl.2007.11.02110.

Béjar-Pizzarro, M., Carrizo, D., Socquet, A., Armijo, R., Barrientos, S., Bondoux, F., Bonvalot, S., Campos, J., Comte, D., de Chabalier, J.B., Charade, O., Delorme, A., Gabalda, G., Galetzka, J., Genricj, J., Nercessian, A., Olcay, M., Ortega, F., Ortega, I., Remy, O., Ruegg, J.C., Simons, M., Valderas, C. and Vigny, C., 2010. Asperities and barriers on the seismogenic zone in North Chile: state-of-the-art after the 2007 Mw 7.7 Tocopilla earthquake inferred by GPS and InSAR data, Geophysical Journal International, 183, 390-406, doi: 10.1111/j.1365246X.2010.04748.x.

Bollinger, L., Avouac, J.P., Cattin, R. and Pandey, M.R., 2004a. Stress buildup in the Himalaya, Journal of Geophysical Research, 109, B11405, doi:10.1029/2003JB002911. 
504

505

506

507

508

509

510

511

512

Bollinger, L., Avouac, J.P., Beyssac, O., Catlos, E.J., Harrison, T.M., Grove, M., Goffé, B. and Sapkota, S., 2004b. Thermal structure and exhumation history of the Lesser Himalaya in central Nepal, Tectonics, 23, TC5015, doi:10.1029/2003TC001564.

Bollinger, L., Perrier, F., Avouac, J.P., Sapkota, S., Gautam, U, and Tiwari, D.R., 2007. Seasonal modulation of seismicity in the Himalaya of Nepal, Geophysical Research Letters, 34, L08304, doi:10.1029/2006GL029192.

Bollinger, L., Tapponnier, P., Sapkota, S.N. and Klinger, Y., 2016. Slip deficit in central Nepal: omen for a repeat of the $1344 \mathrm{AD}$ earthquake?, Earth, Planets and Space, 68:12, doi:10.1186/s40623-016-0389-1.

Burtin, A., 2005. Seismotectonics of the Himalayan Arc from Regional Seismogram Moment Tensor Inversion, Internship report, Oregon State University.

Burtin, A., Bollinger, L., Vergne, J., Cattin R. and Nábělek J. L., 2008. Spectral analysis of seismic noise induced by rivers: A new tool to monitor spatiotemporal changes in stream hydrodynamics, Journal of Geophysical Research, 113, B05301, doi:10.1029/2007JB005034.

Cattin, R. and Avouac, J.P., 2000. Modeling mountain building and seismic cycle in the Himalaya of Nepal, Journal of Geophysical Research, 105(B6), 13389-13407.

Chanard, K., Avouac, J. P., Ramillien G. and Genrich J., 2014. Modeling deformation induced by seasonal variations of continental water in the Himalaya region: Sensitivity to Earth elastic structure, Journal of Geophysical Research: Solid Earth, 119, doi:10.1002/2013JB010451.

Collot, J. Y., Marcaillou, B., Sage, F., Michaud, F., Agudelo, W., Charvis, P., Graindorge, D., Gutscher, M-A. and Spence, G., 2004. Are rupture zone limits of great subduction earthquakes controlled by upper plate structures? Evidence from multichannel seismic 

of Geophysical Research: Solid Earth, 109, B11103.

528 Nature, 305, pp.621-623. subduction interface, Science, 292(5521), 1525-1528. Research Letters, 43, doi: 10.1002/2016GL068083. 10.1002/2015GL064587. 10.1002/2015GL066044.

reflection data acquired across the northern Ecuador-southwest Colombia margin, Journal

Das, S. and Scholz, C.H., 1983. Why large earthquakes do not nucleate at shallow depths,

Dragert, H., Wang, K. and James, T. S., 2001. A silent slip event on the deeper Cascadia

Duputel, Z., Vergne, J., Rivera, L., Wittlinger, G., Farra, V. and Hetényi, G., 2016. The 2015 Gorkha earthquake: A large event illuminating the Main Himalayan Thrust fault, Geophysical

Elliott, J.R., Jolivet, R., Gonzalez, P.J., Avouac, J.P., Hollingsworth, J., Searle, M.P. and Stevens, V.L., 2016. Himalayan megathrust geometry and relation to topography revealed by Gorkha earthquake, Nature geoscience, 9, doi:10.1038/NGE02623.

Fan, W. and Shearer P.M., 2015. Detailed rupture imaging of the 25 April 2015 Nepal earthquake using teleseismic P waves, Geophysical Research Letters, 42, 5744-5752, doi:

Grandin, R., Doin, M-P., Bollinger, L., Pinel-Puyssegur, B., Ducret, G., Jolivet, R. and Sapkota, S.N., 2012. Long-term growth of the Himalaya inferred from interseismic InSAR measurement, Geology, 40, 12, 1059-1062, doi:10.1130/G33154.1.

Grandin, R., Vallée, M., Satriano, C., Lacassin, R., Klinger, Y., Simoes, M., and Bollinger, L., 2015. Rupture process of the $M w=7.92015$ Gorkha earthquake (Nepal): insights into Himalayan megathrust segmentation, Geophysical Research Letters, 42, doi: 
548 Haines, S.S., Klemperer, S.L., Brown, L., Jingru, G., Mechie, J., Meissner, R., Ross, A. and 549 Wenjin, Z., 2003. INDEPTH III seismic data: From surface observations to deep crustal 550 processes in Tibet, Tectonics, 22(8), 1001.

551 Huc, M., Hassani, R., and Chéry, J., 1998. Large earthquake nucleation associated with stress exchange between middle and upper crust, Geophysical Research Letters, 25 (4), 551-554.

553

554

Holtkamp, S. G. and Brudzinski, M. R., 2011. Earthquake swarms in circum-Pacific subduction zones, Earth and Planetary Science Letters, 305(1), 215-225.

Holtkamp, S. G., Pritchard, M. E. and Lohman, R. B., 2011. Earthquake swarms in south America, Geophysical Journal International, 187(1), 128-146.

Jackson, M., and Bilham, R., 1994. Constraints on Himalayan deformation inferred from vertical velocity fields in Nepal and Tibet, Journal of Geophysical Research: Solid Earth, 99(B7), 13897-13912.

Jouanne, F., Mugnier, J.L., Gamond, J.F., Le Fort, P., Pandey, M.R., Bollinger, L., Flouzat, M. and Avouac, J.P., 2004. Current shortening across the Himalayas of Nepal, Geophysical Journal International, 157, 1-14, doi: 10.1111/j.1365-246X.2004.02180.x.

Khanal, S. and Robinson, D.M., 2013. Upper crustal shortening and forward modeling of the Himalayan thrust belt along the Budhi-Gandaki River, central Nepal, International Journal of Earth Science (Geol Rundsch), 102, 1871-1891.

Kobayashi, T., Morishita, Y. and Yarai, H., 2015. Detailed crustal deformation and fault rupture of the 2015 Gorkha earthquake, Nepal, revealed from ScanSAR-based interferograms of ALOS-2, Earth, Planets and Space, 67, 201, doi: 10.1186/s40623-015-0359z. 
570 Kumahara, Y., Chamlagain, D., Upreti, B. N., 2016. Geomorphic features of active faults 571 around the Kathmandu Valley, Nepal, and no evidence of surface rupture associated with 572 the 2015 Gorkha earthquake along the faults, Earth, Planets and Space, 68(1), 1-8.

573 Métois, M., Socquet, A. and Vigny, C., 2012. Interseismic coupling, segmentation and 574 mechanical behavior of the central Chile subduction zone, Journal of Geophysical Research, 575 117, B03406, doi:10.1029/2011JB00736.

576 Murphy, M. A., Taylor, M. H., Gosse, J., Silver, C. R. P., Whipp, D. M. and Beaumont, C., 2014. 577 Limit of strain partitioning in the Himalaya marked by large earthquakes in western Nepal, $578 \quad$ Nature Geoscience, 7(1), 38-42.

579 Nábelek, J., 1984. Determination of earthquake source parameters from inversion of body 580 waves. Ph. D. thesis, Massachusetts Institute of Technology, Cambridge, MA.

Nábelek, J. and Xia, G., 1995. Moment-tensor analysis using regional data: Application to the 25 March, 1993, Scotts Mills, Oregon, earthquake, Geophysical Research Letters, 22(1), 13583 16.

Nabelek, J., Hetényi, G., Vergne, J., Sapkota, S.N., Kafle, B., Jiang, M., Su, H., Chen, J., Huang, B-S. and Hi-CLIMB team, 2009. Underplating in the Himalaya-Tibet Collision Zone Revealed by the Hi-CLIMB Experiment, Science, 325, 1371-1374.

587 Nakata, T., 1989. Active faults of the Himalaya of India and Nepal, Geological Society of 588 America Special Papers, 232, 243-264. 
591

592

593

594

595

596

597

598

599

600

601

602

603

604

605

606

607

608

609

610

Pandey, M.R., Tandukar, R.P., Avouac, J.P., Lavé, J. and Massot, J.P., 1995. Interseismic strain accumulation on the Himalayan Crustal Ramp (Nepal), Geophysical Research Letters, 22, 751-754.

Pandey, M.R., Tandukar, R.P., Avouac, J.P., Vergne, J. and Héritier, T., 1999. Seismotectonics of the Nepal Himalayas from a local seismic network, Journal of Asian Earth Sciences., 17(56), 703-712.

Pearson, O.N. and DeCelles, P.G., 2005. Structural geology and regional tectonic significance of the Ramgarh thrust, Himalayan fold-thrust belt of Nepal, Tectonics, 24, TC4008, doi: 10/1029/2003TC001617.

Robinson, D.M., DeCelles, P.G., Patchett, P.J. and Garzione, C.N, 2001. The kinematic evolution of the Nepalese Himalaya interpreted from $\mathrm{Nd}$ isotopes, Earth and Planetary Science Letters, 192, 4, 507-521, doi:10.1016/S0012-821X(01)00451-4.

Sapkota S.N. ,2011. Surface rupture of 1934 Bihar-Nepal earthquake: implications for seismic hazard in Nepal Himalaya, Ph.D thesis, Institut de Physique du Globe de Paris,France. pp 2292.

Saul, J., Kumar, M.R. and Sarkar D., 2000. Lithospheric and upper mantle structure of the Indian shield, from receiver functions, Geophysical Research Letters, 27, 2357-2360.

Schmidt, D. A. and Gao, H., 2010. Source parameters and time-dependent slip distributions of slow slip events on the Cascadia subduction zone from 1998 to 2008, Journal of Geophysical Research: Solid Earth, 115, B00A18, doi:10.1029/2008JB006045. 
611

612

613

Schulte-Pelkum, V., Monsalve, G., Sheehan, A., Pandey, M.R., Sapkota, S., Bilham, R. and Wu, F., 2005. Imaging the Indian subcontinent beneath the Himalaya, Nature Letters, 435, doi:10.1038/nature03678.

Schwartz, S. Y., Dewey, J. W. and Lay, T. 1989. Influence of fault plane heterogeneity on the seismic behavior in the southern Kurile Islands Arc, Journal of Geophysical Research: Solid Earth, 94(B5), 5637-5649.

Schwartz, S. Y. and Rokosky, J. M., 2007. Slow slip events and seismic tremor at circum-Pacific subduction zones, Reviews of Geophysics, 45(3).

Shrestha, A.B., Wake, C.P., Dibb, J.E, Mayewski, P.A., 2000. Precipitation fluctuations in Nepal Himalaya and its vicinity and relationship with some large scale climatological parameters, International Journal of Climatology, 20, 317 - 327.

Souloumiac, P., Leroy, Y.M., Maillot, B. and Krabbenhoft, K., 2009. Predicting stress distributions in fold-and-thrust belts and accretionary wedges by optimization, Journal of Geophysical Research, 114, B09404, doi: 10.1029/2008JB005986.

Stevens,V.L. and J.P.Avouac, 2015. Interseismic coupling on the main Himalayan thrust, Geophysical Research Letters, 42, 5828-5837, doi:10.1002/2015GL064845.

Szeliga, W., Melbourne, T., Santillan, M. and Miller, M., 2008. GPS constraints on 34 slow slip events within the Cascadia subduction zone, 1997-2005, Journal of Geophysical Research:

Geophysical Research, v.110, Solid Earth, 113, B04404, doi:10.1029/2007JB004948. 
630

631

632

633

634

635

636

637

638

639

640

641

642

643

644

645

646

647

648

649

650

651

Waldhauser, F. and Ellsworth, W.L., 2000. A double-difference earthquake location algorithm: method and application to the Northern Hayward Fault, California, Bulletin Seismological Society of America, 90 (6), 1353-1368.

Yatagai, A., Kamiguchi, K., Arakawa, O., Hamada, A., Yasutomi, N. and Kitoh, A., 2012.

Aphrodite. Constructing a long-term daily gridded precipitation dataset for Asia based on a dense network of rain gauges, America Meteorological Society, Q07023, doi: 10.1029/2011GC003513.

Zahradnik, J., Jansky, J. and Plicka, V., 2008. Detailed waveform inversion for Moment Tensor of $M \sim 4$ events: examples from Corinth Gulf, Greece, Bulletin of the Seismological Society of America, 98 (6), pp. 2756-2771, doi: 10.1785/0120080124.

\section{$\underline{\text { Table caption }}$}

Table 1. Description of the main shocks of the three swarms of 1997. Origin time and epicentral location are from the NSC.

\section{Figure captions}

Figure 1. Seismicity map of Central Nepal from the National Seismological Center of Nepal (Modified from Adhikari et al., 2015). Red dots are the aftershocks of the Gorkha earthquake and the yellow dots indicate epicenters prior to the Gorkha event since 1994. The iso-slip contours of the Gorka earthquake are from Grandin et al., 2015. The black rectangle indicates the area used for Figure 2 and 4. Past earthquakes rupture areas (top right) from Bollinger et al., 2016. MFT: Main Frontal Thrust, MBT: Main Boundary Thrust, MCT: Main Central Thrust. The orange thin lines are the traces of the Southern Tibetan Grabens (Armijo et al., 1986) 
Figure 2. Cumulative number of events during the interseismic period recorded by the NSC from 1994 to 2015 in the area delimited in Figure 1. The black line corresponds to the events of magnitude $M L \geq 2.0$ scaled on the left side. The gray diamonds correspond to the events of magnitude $M L \geq 4.0$ scaled on the right side. $30 \%$ of the events of $M L \geq 4.0$ occurred in 1997 .

Figure 3. Centroid Moment Tensor solution for the Sarshin earthquake occurred on January $31^{\text {st }} 1997$. For each station, observations are shown with solid lines and synthetics with dotted lines. $\mathrm{Z}, \mathrm{R}$ and $\mathrm{T}$ are the vertical, radial and transverse components respectively. Radial components of CHTO, HYB and WUS were discarded because of the high signal-noise ratio. 1 and 0 are the weights used in the inversion.

Figure 4. Spatial distribution of the seismic episode of 1996-1999, north of Kathmandu (see Figure 1): The map shows the relocated seismicity as a function of time and magnitude of Zone 1 and 2 (zones boundary: longitude 85.4 ${ }^{\circ}$ ). The main shock corresponds to the 1997 January $31^{\text {st }} \mathrm{ML}=5.8(\mathrm{Mw} 4.8)$ earthquake with the preferred focal mechanism plane in red. The cross-sections include the relocated seismicity. $A-A^{\prime}$ and $B^{\prime}-B$ cross-sections are orientated N140 and N065, respectively. They stack seismicity located $10 \mathrm{~km}$ for A-A' and 3 $\mathrm{km}$ for $\mathrm{B}^{\prime}-\mathrm{B}$ from each side of the track. The area highlighted in light white correspond to the suspected fault segments at depth activated by the 1997 episode (see Figure 7 for interpretation). The intersection between $A-A^{\prime}$ and $B-B^{\prime}$ cross-sections are indicated with a black cross. The green, blue and pink-brown lines at the bottom of the map are western, central and eastern respectively used in Figure 5.

Figure 5. Time sequence of the seismicity north of Kathmandu. The zones are indicated at the bottom of the map in Figure 4. The Sarshin earthquake is indicated by the yellow star. The red dashed line is the average rate of seismicity (108 events per year). 
Figure 6. Spatio-temporal variations of the seismicity. A) Normalized time sequence of the midcrustal seismicity along the MHT. The curves correspond to the three swarm areas and the yellow one to the inter-swarms area. Gray shadow zone is the time covered in the map. B) Midcrustal seismicity for the period 1996-1997 in yellow, swarm seismicity in red. Orange circles are the Southern Tibetan Grabens north of the swarms.

Figure 7. Schematic evolution of the stress field and structure activation. A) Variation of shear stress and normal stress associated with a transient slip event on the Main Himalayan Thrust in a region with midcrustal tear faults and southern Tibetan grabens. The initial state is shown in black and is assumed tangent to the failure envelope represented by the straight line. 1, 2, and 3 refer to the different areas indicated in B and C. In area 1, s1 and s3 are horizontal, increasing and decreasing respectively, promoting failure. In area 2, s1 is horizontal, striking about north-south and increasing during interseismic deformation and transient slip events, promoting failure. In area 3, s3 is horizontal, striking approximately east-west and decreasing during interseismic deformation, promoting failure. B) and C) Kinematical evolution north of Kathmandu in 1996-1997; orange surface corresponds to the area with a coupling $>50-80 \%$ depending on source (Ader et al., 2012; Grandin et al., 2015). B) Static stress change induced by slip on the tear fault is schematized by Coulomb stress lobes, respectively blue and red for DCFF $<0$ and $>0$. Dotted lines and filled areas correspond respectively to the DCFF calculated for receiver faults with the backthrust and the thrust orientation (more information in Table S1, Table S2, and Figure S8 to S11). C) Activation of the backthrust (in green) and the thrust fault (in salmon) as a consequence of static stress change induced by the tear fault (B). D) Schematic three dimensional block, with vertical exaggeration, of the MHT with the backthrust (green) and the tear fault (purple). Colors on the MHT correspond to the coupling: red: total coupling $(>50-80 \%)$, orange: transition zone 
699 (60\%-40\%), Yellow: completely decoupled (0\%) (Ader et al., 2012; Grandin et al., 2015).

700 White arrows show the kinematics of the structures.

701

702

703 


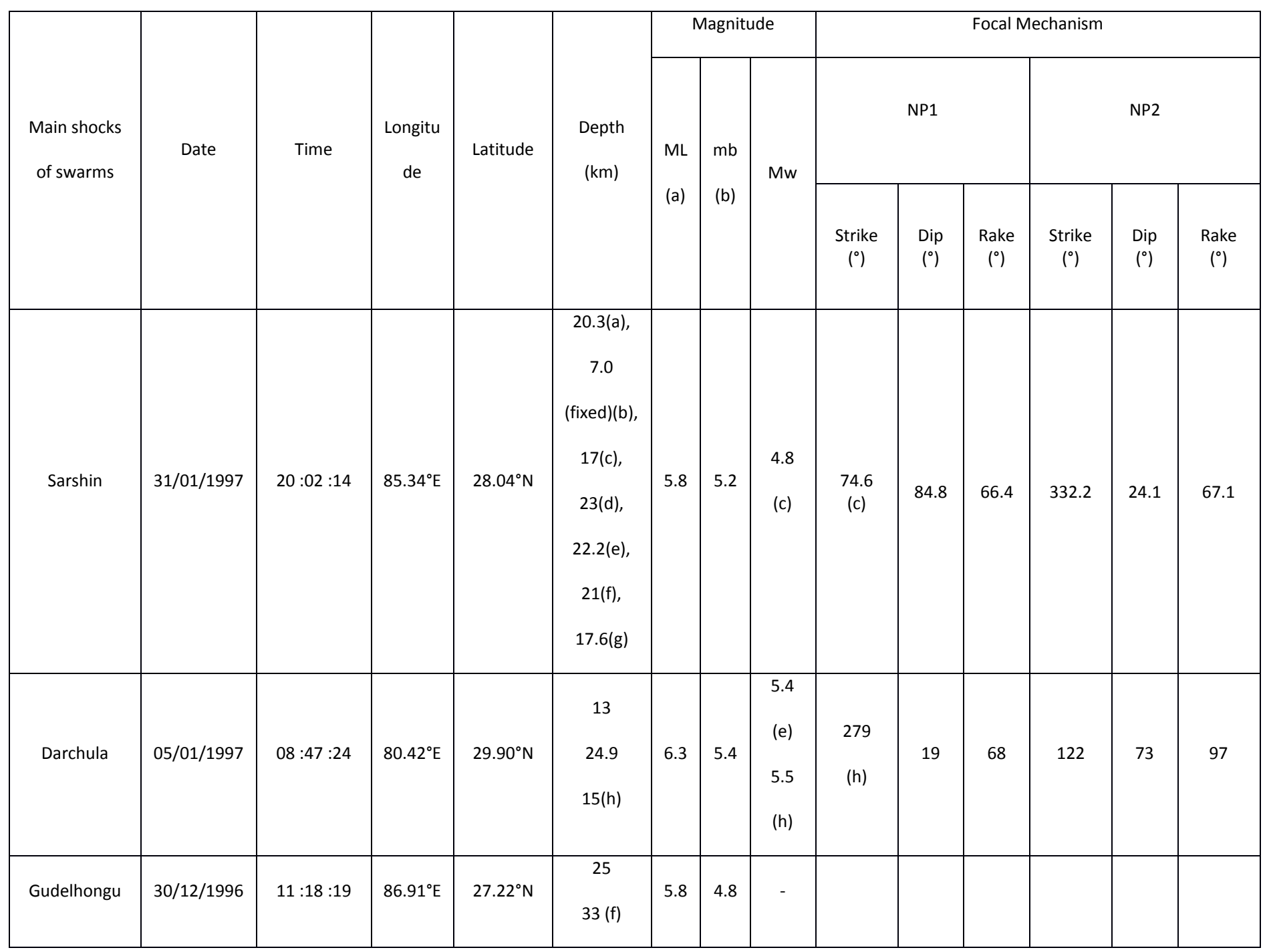
(a) National Seismological Center of Nepal (NSC).
(b) International Seismological Centre, UK (ISC)
(c) Centroid Moment Tensor (in this article)
(d) Geophysical Survey of Russian Academy of Science (MOS)
(e) National Earthquake Information Center, USGS (NEIC)
(f) Experimental (GSETT3) International Data Center, USA (EIDC)
(g) Engdahl, van der Hilst and Buland, USA (EHB)
(h) Global Centroid Moment Tensor 
Figure (figure caption in manuscript_revised)

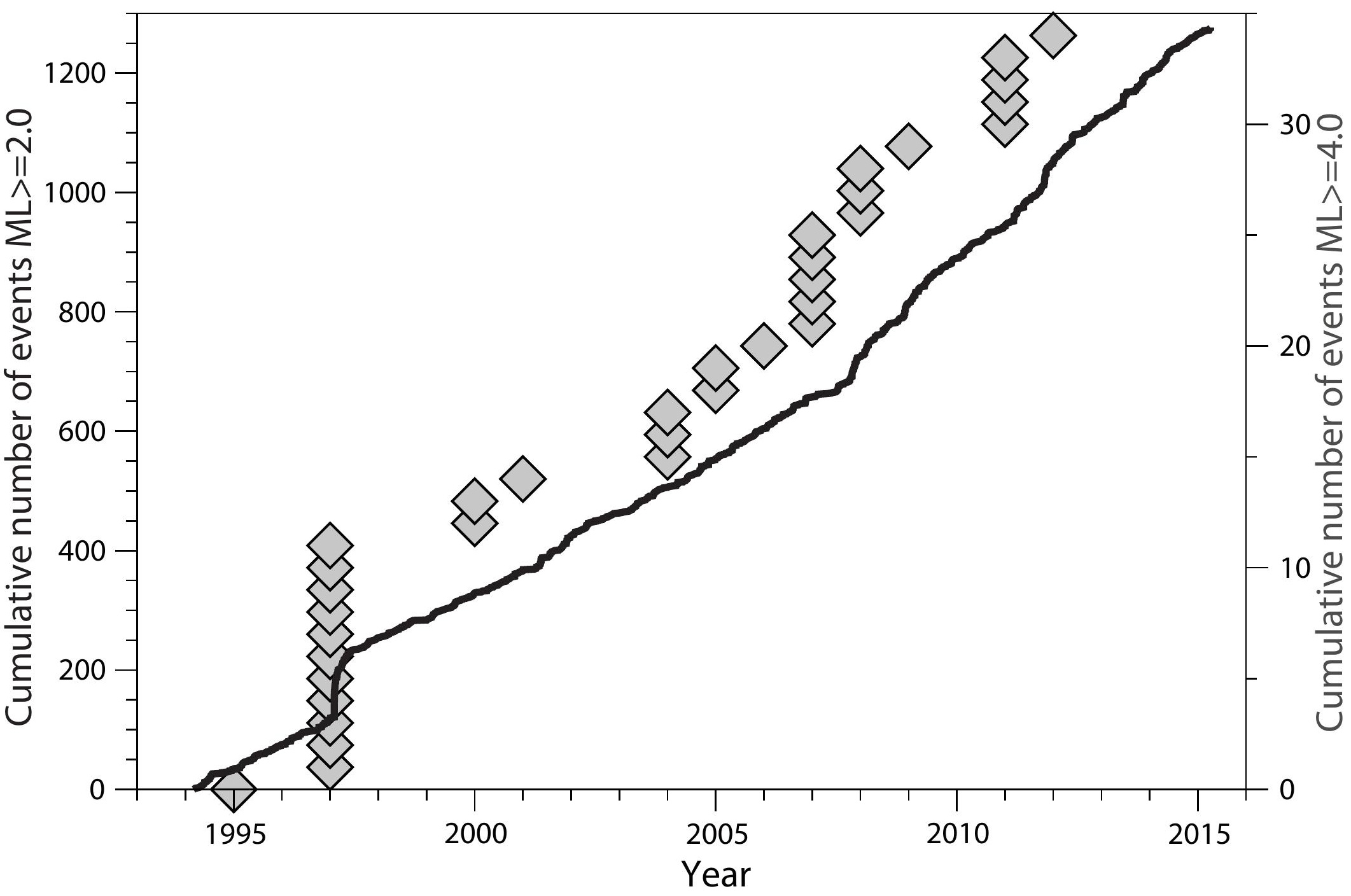


970131_2002, 97/01/31 20:02:16 Mw=4.84 40-100s $17 \mathrm{~km}$

$\mathbf{Z}$

LSA $70^{\circ} 623 \mathrm{~km}$

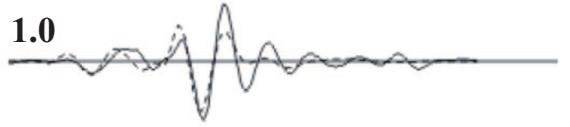

HYB $211^{\circ} 1354 \mathrm{~km}$

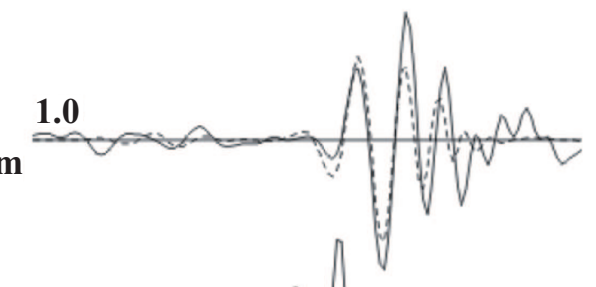

\section{0}

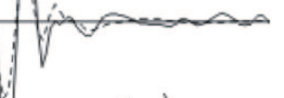

\section{WUS} $341^{\circ} 1576 \mathrm{~km}$
0.0

0.0
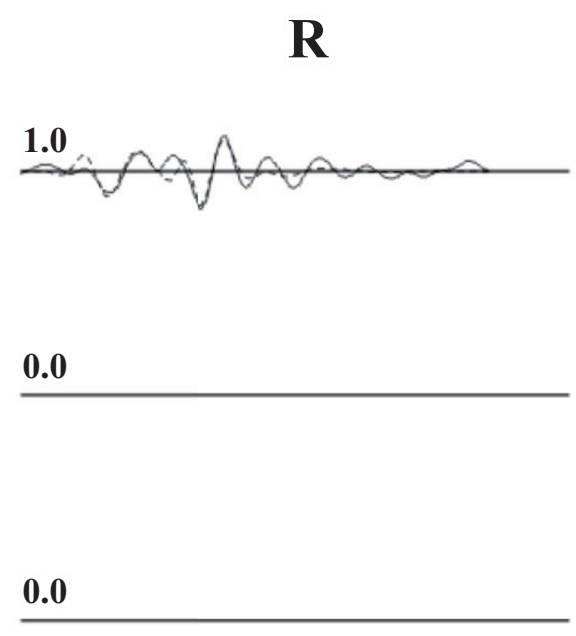

0.0

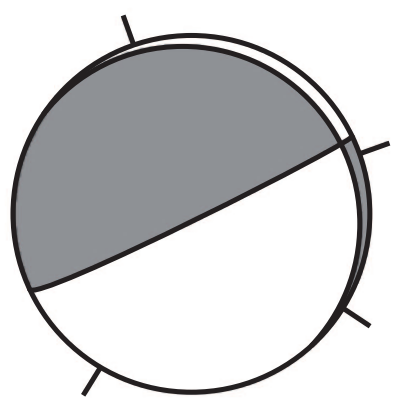

$\mathbf{T}$
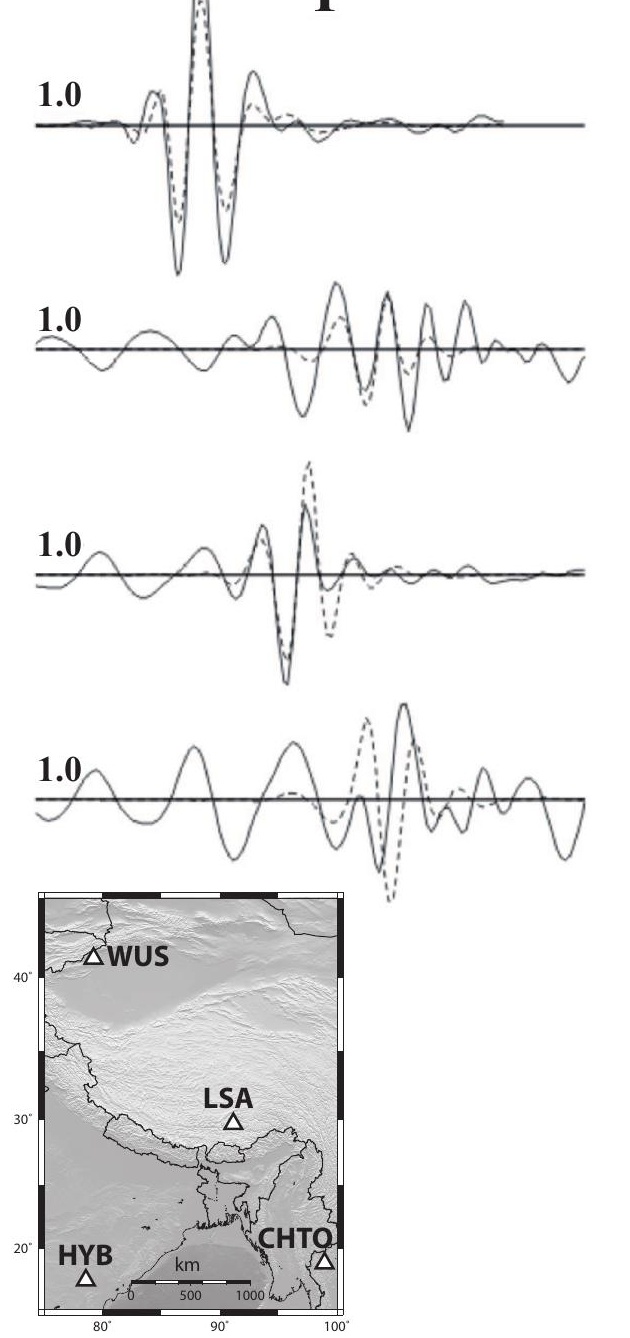
Figure (with caption below and on the same page)

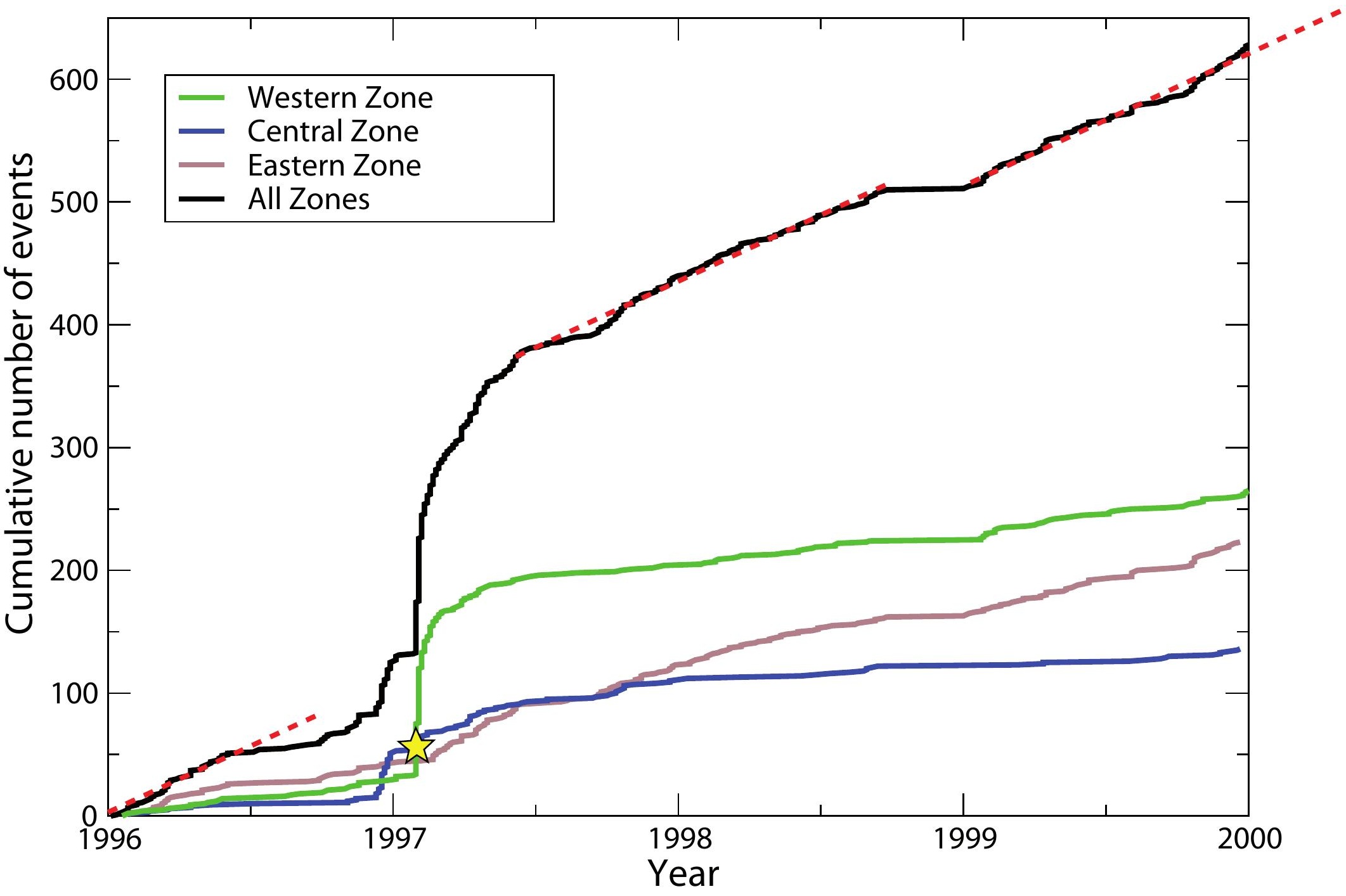



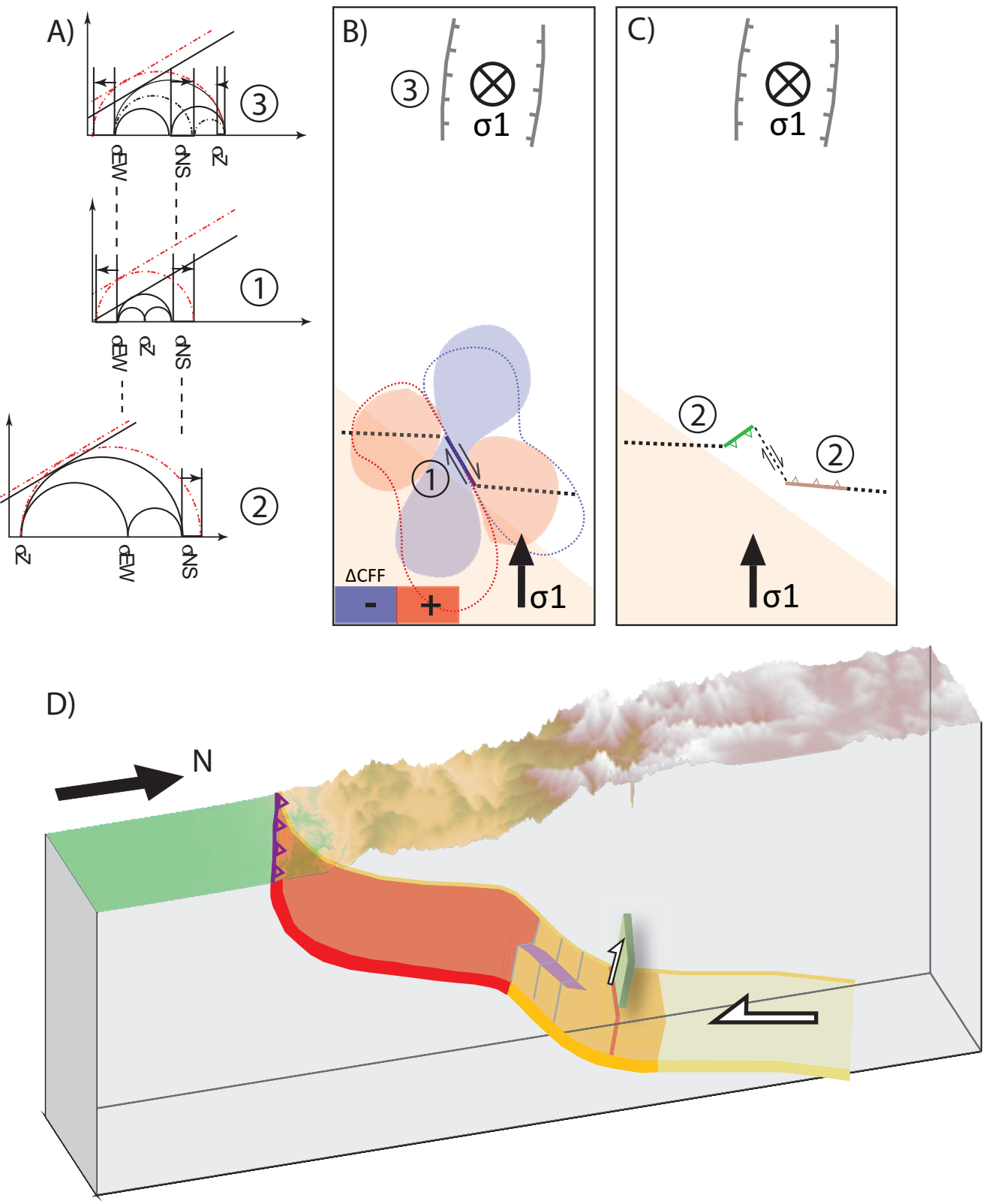

Supplementary material for online publication only
Click here to download Supplementary material for online publication only: SupplMaterial.p Supplementary material for online publication only
Click here to download Supplementary material for online publication only: SupplMaterial.pdf

(1)

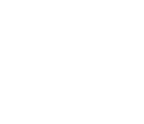

$\sqrt{3}$ (1)

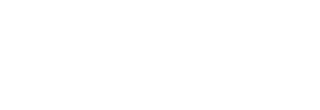

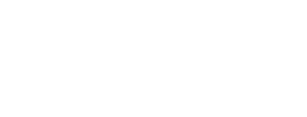
.

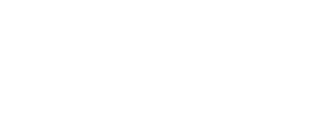
. . . . . . . . .

Click here to download Supplementary material for online publication only: SupplMaterial.p 